\title{
A Unified Iterative Treatment for Solutions of Problems of Split Feasibility and Equilibrium in Hilbert Spaces
}

\author{
Young-Ye Huang' and Chung-Chien Hong ${ }^{2}$ \\ ${ }^{1}$ Department of Accounting Information, Southern Taiwan University of Science and Technology, 1 Nantai Street, \\ Yongkang District, Tainan 71005, Taiwan \\ ${ }^{2}$ Department of Industrial Management, National Pingtung University of Science and Technology, 1 Shuefu Road, \\ Neipu, Pingtung 91201, Taiwan \\ Correspondence should be addressed to Chung-Chien Hong; chong@mail.npust.edu.tw
}

Received 21 May 2013; Revised 30 August 2013; Accepted 1 September 2013

Academic Editor: Simeon Reich

Copyright (C) 2013 Y.-Y. Huang and C.-C. Hong. This is an open access article distributed under the Creative Commons Attribution License, which permits unrestricted use, distribution, and reproduction in any medium, provided the original work is properly cited.

\begin{abstract}
We at first raise the so called split feasibility fixed point problem which covers the problems of split feasibility, convex feasibility, and equilibrium as special cases and then give two types of algorithms for finding solutions of this problem and establish the corresponding strong convergence theorems for the sequences generated by our algorithms. As a consequence, we apply them to study the split feasibility problem, the zero point problem of maximal monotone operators, and the equilibrium problem and to show that the unique minimum norm solutions of these problems can be obtained through our algorithms. Since the variational inequalities, convex differentiable optimization, and Nash equilibria in noncooperative games can be formulated as equilibrium problems, each type of our algorithms can be considered as a generalized methodology for solving the aforementioned problems.
\end{abstract}

\section{Introduction}

Throughout this paper, $\mathscr{H}$ denotes a real Hilbert space with inner product $\langle\cdot, \cdot\rangle$ and the norm $\|\cdot\|, I$ the identity mapping on $\mathscr{H}, \mathbb{N}$ the set of all natural numbers, and $\mathbb{R}$ the set of all real numbers. For a self-mapping $T$ on $\mathscr{H}, \operatorname{Fix}(T)$ denotes the set of all fixed points of $T$. If $M: \mathscr{H} \rightarrow 2^{\mathscr{H}}$ is a set-valued mapping; then $\mathscr{D}(M)$ denotes its domain, that is, $\mathscr{D}(M)=$ $\{x \in \mathscr{H}: M(x) \neq \emptyset\}$.

Let $C$ and $Q$ be nonempty closed convex subsets of two Hilbert spaces $\mathscr{H}_{1}$ and $\mathscr{H}_{2}$, respectively, and let $A$ : $\mathscr{H}_{1} \rightarrow \mathscr{H}_{2}$ be a bounded linear mapping. The split feasibility problem (SFP) is the problem of finding a point with the property

$$
x^{*} \in C, \quad A x^{*} \in Q .
$$

The SFP was first introduced by Censor and Elfving [1] for modeling inverse problems which arise from phase retrievals and medical image reconstruction. Recently, it has been found that the SFP can also be used to model the intensitymodulated radiation therapy. For details, the readers are referred to $\mathrm{Xu}$ [2] and the references therein.

Assume that the SFP has a solution. There are many iterative methods designed to approximate its solutions. The most popular algorithm is the CQ algorithm introduced by Byrne $[3,4]$.

Start with any $x_{1} \in \mathscr{H}_{1}$ and generate a sequence $\left\{x_{n}\right\}$ through the iteration

$$
x_{n+1}=P_{C}\left[I-\gamma A^{*}\left(I-P_{\mathrm{Q}}\right) A\right] x_{n},
$$

where $\gamma \in\left(0,2 /\|A\|^{2}\right), A^{*}$ the adjoint of $A$, and $P_{C}$ and $P_{\mathrm{Q}}$ are the metric projections onto $C$ and $Q$, respectively.

The sequence $\left\{x_{n}\right\}$ generated by the CQ algorithm (2) converges weakly to a solution of SFP(1), cf. [2-4]. Under the assumption that $\mathrm{SFP}(1)$ has a solution, it is known that a point $x^{*} \in \mathscr{H}_{1}$ solves SFP(1) if and only if $x^{*}$ is a fixed point of the operator

$$
P_{C}\left[I-\gamma A^{*}\left(I-P_{\mathrm{Q}}\right) A\right],
$$


cf. [2], where Xu also proposed the regularized method,

$$
x_{n+1}=P_{C}\left[I-\gamma_{n}\left(A^{*}\left(I-P_{\mathrm{Q}}\right) A+\alpha_{n} I\right)\right] x_{n},
$$

and proved that the sequence $\left\{x_{n}\right\}$ converges strongly to the minimum norm solution of $\mathrm{SFP}(1)$ provided that the parameters $\left\{\alpha_{n}\right\}$ and $\left\{\gamma_{n}\right\}$ verify some suitable conditions. This regularized method was further investigated by Yao et al. [5] and Yao et al. [6].

Putting $S=P_{C}$ and $T=P_{Q}, \operatorname{SFP}(1)$ is of the forms:

$$
\begin{aligned}
& \text { find } x^{*} \in \mathscr{H}_{1} \\
& \text { so that } x^{*} \in \operatorname{Fix}(S), \quad A x^{*} \in \operatorname{Fix}(T) .
\end{aligned}
$$

As a metric projection is firmly nonexpansive, it is reasonable to require the $S$ and $T$ in (5) to be firmly nonexpansive only and call it a split feasibility fixed point problem (SFFP). Many interesting problems in the literature can be described as SFFP.

(i) A set-valued map $M: \mathscr{H} \rightarrow 2^{\mathscr{H}}$ is called monotone if

$$
\langle x-y, u-v\rangle \geq 0
$$

for all $x, y \in \mathscr{D}(M)$ and for any $u \in M(x), v \in M(y) . M$ is said to be maximal monotone if its graph $\{(x, u): x \in \mathscr{H}, u \in$ $M(x)\}$ is not properly contained in the graph of any other monotone operator. A point $v \in \mathscr{H}$ is called a zero point of a maximal monotone operator $M$ if $0 \in M(v)$. The set of all zero points of $M$ is denoted by $M^{-1} 0$, which is equal to $\operatorname{Fix}\left(J_{\alpha}^{M}\right)$ for any $\alpha>0$, where $J_{\alpha}^{M}$ denotes the resolvent of a monotone operator $M$; that is, $J_{\alpha}^{M}(x)=(I+\alpha M)^{-1}(x)$ for any $x \in \mathscr{H}$. It is known that for any $\alpha>0, J_{\alpha}^{M}$ is firmly nonexpansive. Now, let $M$ and $N$ be two maximal monotone operators on $\mathscr{H}_{1}$ and $\mathscr{H}_{2}$, respectively. Replacing $C$ and $Q$ with $M^{-1} 0=\operatorname{Fix}\left(J_{\alpha}^{M}\right)$ and $N^{-1} 0=\operatorname{Fix}\left(J_{\beta}^{N}\right)$, respectively, in (1), the SFP becomes a SFFP:

$$
\begin{gathered}
\text { find } x^{*} \in \mathscr{H}_{1} \\
\text { so that } x^{*} \in \operatorname{Fix}\left(J_{\alpha}^{M}\right), \quad A x^{*} \in \operatorname{Fix}\left(J_{\beta}^{N}\right) .
\end{gathered}
$$

Putting $A=I$, the previous SFFP is reduced to the common zero point problem of two maximal monotone operators:

$$
\text { find } x^{*} \in \mathscr{H}_{1} \text { so that } x^{*} \in M^{-1} 0 \cap N^{-1} 0 \text {. }
$$

(ii) Let $f: C \times C \rightarrow \mathbb{R}$. An equilibrium problem is the problem of finding $\widehat{x} \in C$ such that

$$
f(\widehat{x}, y) \geq 0, \quad \forall y \in C,
$$

whose solution set is denoted by $\operatorname{EP}(f)$. For solving an equilibrium problem, we usually assume that the function $f$ satisfies the following conditions:

(A1) $f(x, x)=0$, for all $x \in C$;

(A2) $f$ is monotone, that is, $f(x, y)+f(y, x) \leq 0$, for all $x \in C$;

(A3) for all $x, y, z \in C, \lim \sup _{t \downarrow 0} f((1-t) x+t z, y) \leq$ $f(x, y)$;
(A4) for all $x \in C, f(x, \cdot)$ is convex and lower semicontinuous.

Blum and Oettli [7] and Aoyama et al. [8] showed that there exists a unique $z \in C$ such that

$$
f(z, y)+\frac{1}{r}\langle y-z, z-x\rangle \geq 0, \quad \forall y \in C .
$$

Moreover, For $r>0$, define $J_{r}^{f}: \mathscr{H} \rightarrow C$ by

$$
J_{r}^{f} x=\left\{z \in C: f(z, y)+\frac{1}{r}\langle y-z, z-x\rangle \geq 0, \forall y \in C\right\}
$$

for all $x \in \mathscr{H}$. Combettes and Hirstoaga [9] showed that there hold
(a) $J_{r}^{f}$ is single-valued;
(b) $J_{r}^{f}$ is firmly nonexpansive;
(c) $\operatorname{Fix}\left(J_{r}^{f}\right)=\operatorname{EP}(f)$;
(d) $\operatorname{EP}(f)$ is closed and convex.

Now, let $f: C \times C \rightarrow \mathbb{R}$ and $g: Q \times Q \rightarrow \mathbb{R}$ be two functions satisfying conditions (A1)-(A4). Replacing $C$ and $Q$ with $\operatorname{EP}(f)=\operatorname{Fix}\left(J_{\alpha}^{f}\right)$ and $\operatorname{EP}(g)=\operatorname{Fix}\left(J_{\beta}^{g}\right)$, respectively, in (1), the SFP becomes a SFFP:

$$
\begin{gathered}
\text { find } x^{*} \in \mathscr{H}_{1} \\
\text { so that } x^{*} \in \operatorname{Fix}\left(J_{\alpha}^{f}\right), \quad A x^{*} \in \operatorname{Fix}\left(J_{\beta}^{g}\right) .
\end{gathered}
$$

Putting $\mathscr{H}_{1}=\mathscr{H}_{2}, C=Q$, and $A=I$, the previous SFFP is reduced to the common equilibrium problem:

$$
\text { find } x^{*} \in C
$$

so that $f\left(x^{*}, y\right) \geq 0, \quad g\left(x^{*}, y\right) \geq 0, \quad \forall y \in C$.

(iii) When $\mathscr{H}_{1}=\mathscr{H}_{2}=\mathscr{H}$, and the bounded linear operator $A$ is the identity mapping, $\operatorname{SFP}(1)$ is reduced to the convex feasibility problem (CFP):

$$
\text { find } x^{*} \in \mathscr{H} \quad \text { so that } x^{*} \in C \cap Q \text {, }
$$

which in turn can be described as a SFFP:

$$
\begin{gathered}
\text { find } x^{*} \in \mathscr{H} \\
\text { so that } x^{*} \in \operatorname{Fix}(S), \quad A x^{*} \in \operatorname{Fix}(T),
\end{gathered}
$$

where $S=P_{C}$ and $T=P_{Q}$. Although $\operatorname{SFFP}(5)$ contains CFP as a special case, it cannot cover the multiple-set split convex feasibility problem described in [10].

In this paper, we are concerned with iterative methods for $\operatorname{SFFP}(5)$. We derive some weak convergence theorems for $\operatorname{SFFP}(5)$ in Section 3. In Section 4, we describe $\operatorname{SFFP}(5)$ in a more general form. 
Let $\left\{S_{n}\right\}$ and $\left\{T_{n}\right\}$ be two families of firmly nonexpansive self-mappings on $\mathscr{H}_{1}$ and $\mathscr{H}_{2}$, respectively, so that $\cap_{n=1}^{\infty} \operatorname{Fix}\left(S_{n}\right) \neq \emptyset$ and $\cap_{n=1}^{\infty} \operatorname{Fix}\left(T_{n}\right) \neq \emptyset$

$$
\text { find } x^{*} \in \mathscr{H}_{1}
$$$$
\text { so that } x^{*} \in \cap_{n=1}^{\infty} \operatorname{Fix}\left(S_{n}\right), \quad A x^{*} \in \cap_{n=1}^{\infty} \operatorname{Fix}\left(T_{n}\right)
$$

and obtain the following main result.

Let $\left\{a_{n}\right\},\left\{b_{n}\right\},\left\{c_{n}\right\}$, and $\left\{d_{n}\right\}$ be sequences in $[0,1]$ with $a_{n}+b_{n}+c_{n}+d_{n}=1$ and $a_{n} \in(0,1)$ for all $n \in \mathbb{N}$. Let $\left\{\gamma_{n}\right\}$ be a sequence in $\left(0,2 /\|A\|^{2}\right)$ and let $\left\{e_{n}\right\}$ be a bounded sequence in $\mathscr{H}_{1}$. Suppose that the solution set $\Omega$ of $\operatorname{SFFP}(16)$ is nonempty. For any $u \in \mathscr{H}_{1}$, start with an arbitrary $x_{1} \in \mathscr{H}_{1}$ and define a sequence $\left\{x_{n}\right\}$ by

$$
x_{n+1}=a_{n} u+b_{n} x_{n}+c_{n} S_{n}\left[I-\gamma_{n} A^{*}\left(I-T_{n}\right) A\right] x_{n}+d_{n} e_{n} .
$$

Then, the sequence $\left\{x_{n}\right\}$ converges strongly to $P_{\Omega} u$ provided that the following conditions are satisfied:

(i) $\lim _{n \rightarrow \infty} a_{n}=\lim _{n \rightarrow \infty}\left(d_{n} / a_{n}\right)=0, \sum_{n=1}^{\infty} a_{n}=\infty$,
$\sum_{n=1}^{\infty} d_{n}<\infty$;

(ii) $\lim _{n \rightarrow \infty} \inf c_{n}\left(2 \gamma_{n}-\gamma_{n}^{2}\|A\|^{2}\right)>0, \lim _{n \rightarrow \infty} \inf b_{n} c_{n}>$ 0 ;

(iii) there are two nonnegative real-valued functions $\kappa_{1}$ and $\kappa_{2}$ on $\mathbb{N}$ with

$$
\begin{gathered}
\left\|S_{m} x-x\right\| \leq \kappa_{1}(m)\left\|S_{n} x-x\right\|, \\
\forall m \in \mathbb{N}, \forall n \geq m, \forall x \in \mathscr{H}_{1}, \\
\left\|T_{m} y-y\right\| \leq \kappa_{2}(m)\left\|T_{n} y-y\right\|, \\
\forall m \in \mathbb{N}, \forall n \geq m, \forall y \in \mathscr{H}_{2} .
\end{gathered}
$$

Based on the concept of using contractions to approximate nonexpansive mappings, another type of algorithms for SFFP(5) is also introduced, and the corresponding strong convergence theorem for the sequence generated by such algorithm is given too.

In Section 5, since resolvents of monotone operators are firmly nonexpansive, we replace the sequences $\left\{S_{n}\right\}$ and $\left\{T_{n}\right\}$ of firmly nonexpansive mappings in the previous condition (iii) by two sequences of resolvents of maximal monotone operators. Then, the proposed algorithm becomes a scheme to approach the minimum norm solution of zero point problem of maximal monotone operators and the equilibrium problem. It is worth noting that as Blum and Oettli [7] showed that the variational inequalities, convex differentiable optimization, and Nash equilibria in noncooperative games can be formulated as equilibrium problems, the proposed algorithm can be considered as a generalized methodology for solving all aforementioned problems.

\section{Preliminaries}

In order to facilitate our investigation in this paper, we recall some basic facts. A mapping $S: \mathscr{H} \rightarrow \mathscr{H}$ is said to be (i) nonexpansive if

$$
\|S x-S y\| \leq\|x-y\|, \quad \forall x, y \in \mathscr{H} ;
$$

(ii) firmly nonexpansive if

$$
\|S x-S y\|^{2} \leq\langle x-y, S x-S y\rangle, \quad \forall x, y \in \mathscr{H} ;
$$

(iii) $\lambda$-averaged by $G$ if

$$
S=(1-\lambda) I+\lambda G
$$

for some $\lambda \in(0,1)$ and some nonexpansive mapping G;

(iv) $v$-inverse strongly monotone ( $\nu$-ism), with $v>0$, if

$$
\langle x-y, S x-S y\rangle \geq v\|S x-S y\|^{2}, \quad \forall x, y \in \mathscr{H} .
$$

If $S$ is nonexpansive, then the fixed point set $\operatorname{Fix}(S)$ of $S$ is closed and convex, cf. [11]. If $S=(1-\lambda) I+\lambda G$ is averaged, then $S$ is nonexpansive with $\operatorname{Fix}(S)=\operatorname{Fix}(G)$. It is well known that $S$ is firmly nonexpansive if and only if it is $1 / 2$-averaged, cf. [11], and so is $I-S$. Here we would like to mention that the term "averaged mapping" originated in $[12,13]$. In [12], Baillon el at. showed that if $S$ is a $\lambda$-averaged mapping by $G$ on a nonempty closed convex subset $C$ of a uniformly convex Banach space, then $\operatorname{Fix}(G)=\phi$ if and only if $\lim _{n \rightarrow \infty}\left\|S^{n} x\right\|=\infty$ for all $x$ in C. Moreover, in [13], Bruck and Reich showed that if the above $C$ satisfies $C=-C$ and $S$ is odd, then $\left\{S^{n} x\right\}$ converges strongly to a fixed point of $G$.

Let $C$ be a nonempty closed convex subset of $\mathscr{H}$. The metric projection $P_{C}$ from $\mathscr{H}$ onto $C$ is the mapping that assigns each $x \in \mathscr{H}$ the unique point $P_{C} x$ in $C$ with the property

$$
\left\|x-P_{C} x\right\|=\min _{y \in C}\|y-x\| .
$$

It is known that $P_{C}$ is firmly nonexpansive and characterized by the inequality: for any $x \in \mathscr{H}$,

$$
\left\langle x-P_{C} x, y-P_{C} x\right\rangle \leq 0, \quad \forall y \in C .
$$

We need some lemmas that will be quoted in the sequel.

Lemma 1 (see [4]). If $S$ is a self-mapping on $\mathscr{H}$, then the following assertions hold.

(a) $S$ is nonexpansive if and only if the complement $I-S$ is 1/2-averaged.

(b) If $S$ is $\gamma$-ism and $\gamma>0$, then $\gamma S$ is $(\nu / \gamma)$-ism.

(c) $S$ is $\alpha$-averaged if and only if $I-S$ is $(1 / 2 \alpha)$-ism.

(d) If $S$ is $\alpha_{1}$-averaged and $T$ is $\alpha_{2}$-averaged, then the composite ST is $\alpha_{1}+\alpha_{2}-\alpha_{1} \alpha_{2}$-averaged.

(e) If $S$ and $U$ are averaged on $\mathscr{H}$ so that $\operatorname{Fix}(S) \cap$ $\operatorname{Fix}(U) \neq \emptyset$, then

$$
\operatorname{Fix}(S U)=\operatorname{Fix}(S) \cap \operatorname{Fix}(U) .
$$


For $\alpha>0$, the resolvent $J_{\alpha}^{A}$ of a maximal monotone operator $A$ on $\mathscr{H}$ has the following properties.

Lemma 2. Let $A$ be a maximal monotone operator on $\mathscr{H}$. Then,

(a) $J_{\alpha}^{A}$ is single-valued and firmly nonexpansive;

(b) $\mathscr{D}\left(J_{\alpha}^{A}\right)=\mathscr{H}$ and $\operatorname{Fix}\left(J_{\alpha}^{A}\right)=A^{-1} 0$;

(c) (the resolvent identity) for $\mu, \lambda>0$, the following identity holds:

$$
J_{\mu}^{A} x=J_{\lambda}^{A}\left(\frac{\lambda}{\mu} x+\left(1-\frac{\lambda}{\mu}\right) J_{\mu}^{A} x\right), \quad \forall x \in \mathscr{H} .
$$

We referred readers to [14-24] for maximal monotone operators and their related algorithms.

Lemma 3. Let $x, y, z \in \mathscr{H}$. Then,

(a) $\|x+y\|^{2} \leq\|x\|^{2}+2\langle y, x+y\rangle$;

(b) for any $\lambda \in \mathbb{R}$,

$$
\begin{aligned}
& \|\lambda x+(1-\lambda) y\|^{2} \\
& =\lambda\|x\|^{2}+(1-\lambda)\|y\|^{2}-\lambda(1-\lambda)\|x-y\|^{2} ;
\end{aligned}
$$

(c) for $a, b, c \in[0,1]$ with $a+b+c=1$,

$$
\begin{aligned}
\|a x+b y+c z\|^{2}= & a\|x\|^{2}+b\|y\|^{2}+c\|z\|^{2} \\
& -a b\|x-y\|^{2}-a c\|x-z\|^{2} \\
& -b c\|y-z\|^{2} .
\end{aligned}
$$

Lemma 4 (see [11] (demiclosedness principle)). Let $S$ be a nonexpansive self-mapping on $\mathscr{H}$ and suppose that $\left\{x_{n}\right\}$ is a sequence in $\mathscr{H}$ such that $\left\{x_{n}\right\}$ converges weakly to some $z \in \mathscr{H}$ and $\lim _{n \rightarrow \infty}\left\|x_{n}-S x_{n}\right\|=0$. Then, $S z=z$.

Lemma 5 (see [23]). Let $\left\{s_{n}\right\}$ be a sequence of nonnegative real numbers satisfying

$$
s_{n+1} \leq\left(1-\alpha_{n}\right) s_{n}+\alpha_{n} \mu_{n}+\nu_{n}, \quad n \in \mathbb{N},
$$

where $\left\{\alpha_{n}\right\},\left\{\mu_{n}\right\}$, and $\left\{\nu_{n}\right\}$ verify the following conditions:

(i) $\left\{\alpha_{n}\right\} \subseteq[0,1], \sum_{n=1}^{\infty} \alpha_{n}=\infty$;

(ii) $\limsup _{n \rightarrow \infty} \mu_{n} \leq 0$;

(iii) $\left\{v_{n}\right\} \subseteq[0, \infty)$ and $\sum_{n=1}^{\infty} v_{n}<\infty$.

Then, $\lim _{n \rightarrow \infty} s_{n}=0$.

Lemma 6 (see [25]). Let $\left\{s_{n}\right\}$ be a sequence in $\mathbb{R}$ that does not decrease at infinity in the sense that there exists a subsequence $\left\{s_{n_{i}}\right\}$ such that

$$
s_{n_{i}}<s_{n_{i}+1}, \quad \forall i \in \mathbb{N} .
$$

For any $k \in \mathbb{N}$, define $m_{k}=\max \left\{j \leq k: s_{j}<s_{j+1}\right\}$. Then, $m_{k} \rightarrow \infty$ as $k \rightarrow \infty$ and $\max \left\{s_{m_{k}}, s_{k}\right\} \leq s_{m_{k}+1}$, for all $k \in \mathbb{N}$.

\section{Weak Convergence Theorems}

In this section, we at first transform $\operatorname{SFFP(5)~into~a~fixed~point~}$ problem for the operator $S\left(I-\gamma A^{*}(I-T) A\right)$, where $\gamma$ is any positive real number. And then use fixed point algorithms to solve SFFP(5). From now on until the end of this paper, unless we state specifically, $S$ and $S_{n}, n \in \mathbb{N}$ (resp., $T$ and $T_{n}, n \in$ $\mathbb{N}$ ) are firmly nonexpansive self-mappings on $\mathscr{H}_{1}$ (resp., $\mathscr{H}_{2}$ ), and $A$ denotes a bounded linear operator from $\mathscr{H}_{1}$ into $\mathscr{H}_{2}$ with adjoint $A^{*}$.

Lemma 7. Let $S$ be a firmly nonexpansive self-mapping on $\mathscr{H}$ with $\operatorname{Fix}(S) \neq \emptyset$. Then, for any $x \in \mathscr{H}$, one has

$$
\langle x-S x, v-S x\rangle \leq 0, \quad \forall v \in \operatorname{Fix}(S) .
$$

Proof. Since $v \in \operatorname{Fix}(S)$ and $S$ is firmly nonexpansive, we have

$$
\begin{aligned}
\|S x-v\|^{2} & =\|S x-S v\|^{2} \\
& \leq\langle x-v, S x-S v\rangle \\
& =\langle x-v, S x-v\rangle,
\end{aligned}
$$

and hence,

$$
\begin{aligned}
\langle x-S x, v-S x\rangle= & \langle x-v, v-S x\rangle \\
& +\langle v-S x, v-S x\rangle \\
= & \|v-S x\|^{2}-\langle x-v, S x-v\rangle \\
\leq & \|v-S x\|^{2}-\|S x-v\|^{2}=0 .
\end{aligned}
$$

Although $\langle x-S x, v-S x\rangle \leq 0$, for all $v \in \operatorname{Fix}(S)$ is similar to the characterization inequality (24) for the metric projection $P_{\text {Fix }(S)}$, as $S x$ needs not to be in $\operatorname{Fix}(S)$, it is in general different from $P_{\operatorname{Fix}(S)}(x)$. For example, let $S x=3 x / 4$ for all $x \in \mathbb{R}$, which is obviously firmly nonexpansive with $\operatorname{Fix}(S)=\{0\}$. Thus, $P_{\text {Fix }(S)}(x)=0$ for all $x \in \mathbb{R}$, while $S x \neq 0$ for all $x \neq 0$.

Proposition 8. For any $\gamma \in\left(0,2 /\|A\|^{2}\right)$, the operator $I-$ $\gamma A^{*}(I-T) A$ is $\gamma\|A\|^{2} / 2$-averaged and $S\left[I-\gamma A^{*}(I-T) A\right]$ is $\left(2+\gamma\|A\|^{2}\right) / 4$-averaged.

Proof. Using the fact that $T$ is firmly nonexpansive, it is routine to show that $A^{*}(I-T) A$ is $1 /\|A\|^{2}$-ism, and so $\gamma A^{*}(I-$ T) $A$ is $1 / \gamma\|A\|^{2}$-ism by Lemma 1(b). Thus, Lemma 1 (c) shows that $I-\gamma A^{*}(I-T) A$ is $\gamma\|A\|^{2} / 2$-averaged. As $S$ is firmly nonexpansive, it is $1 / 2$-averaged. Therefore, $S\left[I-\gamma A^{*}(I-T) A\right]$ is $(1 / 2)+\left(\gamma\|A\|^{2} / 2\right)-\left(\gamma\|A\|^{2} / 4\right)=\left(\left(2+\gamma\|A\|^{2}\right) / 4\right)$-averaged by Lemma $1(\mathrm{~d})$.

Proposition 9. Let $\Omega$ be the solution set of $\operatorname{SFFP}(5)$; that is, $\Omega=\operatorname{Fix}(S) \cap A^{-1}(\operatorname{Fix}(T))$. For any $\gamma \in\left(0,2 /\|A\|^{2}\right)$, let $U=$ $I-\gamma A^{*}(I-T) A$. Suppose that $\Omega \neq \emptyset$. Then, $\operatorname{Fix}(S U)=\operatorname{Fix}(S) \cap$ $\operatorname{Fix}(U)=\Omega$. 
Proof. If $x^{*}$ solves $\operatorname{SFFP}(5)$, we have $x^{*} \in \operatorname{Fix}(S)$ and $A x^{*} \in$ $\operatorname{Fix}(T)$. Now, note that $A x^{*} \in \operatorname{Fix}(T)$ implies

$$
(I-T) A x^{*}=0
$$

and so

$$
\left(I-\gamma A^{*}(I-T) A\right) x^{*}=x^{*}
$$

which means that $x^{*} \in \operatorname{Fix}(U)$. Consequently, $x^{*} \in \operatorname{Fix}(S) \cap$ $\operatorname{Fix}(U)$. This shows that $\Omega \subseteq \operatorname{Fix}(S) \cap \operatorname{Fix}(U)$.

For the inverse inclusion, let $x^{*}$ be any member of $\operatorname{Fix}(S) \cap \operatorname{Fix}(U)$ and pick $v \in \Omega$. It is readily seen from $x^{*} \in \operatorname{Fix}(U)$ that

$$
A^{*}(I-T) A x^{*}=0 .
$$

Since $A v \in \operatorname{Fix}(T)$, an application of Lemma 7 yields

$$
\left\langle(I-T) A x^{*}, A v-T A x^{*}\right\rangle \leq 0,
$$

which together with (36) implies that

$$
\begin{aligned}
\left\|(I-T) A x^{*}\right\|^{2}= & \left\langle(I-T) A x^{*}, A x^{*}-A v\right\rangle \\
& +\left\langle(I-T) A x^{*}, A v-T A x^{*}\right\rangle \\
\leq & \left\langle(I-T) A x^{*}, A x^{*}-A v\right\rangle \\
= & \left\langle A^{*}(I-T) A x, x^{*}-v\right\rangle=0 .
\end{aligned}
$$

This comes to conclude that $A x^{*} \in \operatorname{Fix}(T)$, and hence $x^{*} \in$ $\Omega$ once we note that $x^{*} \in \operatorname{Fix}(S)$. Finally, since $\Omega \neq \emptyset$ by assumption, we have $\operatorname{Fix}(S) \cap \operatorname{Fix}(U)=\Omega \neq \emptyset$. Thus, $\operatorname{Fix}(S U)=$ $\operatorname{Fix}(S) \cap \operatorname{Fix}(U)$ follows from Lemma $1(\mathrm{e})$.

Proposition 10 (see $[2,4])$. If $G$ is an averaged self-mapping on $\mathscr{H}$ with $\operatorname{Fix}(G) \neq \emptyset$, then for any $x \in \mathscr{H}$, the sequence $\left\{G^{n} x\right\}$ converges weakly to a fixed point of $G$.

An immediate consequence of Propositions 8, 9, and 10 is the following convergence result.

Theorem 11. Assume that SFFP(5) has a solution. Then, for any $\gamma \in\left(0,2 /\|A\|^{2}\right)$ and starting with any point $x_{1} \in \mathscr{H}$, the sequence $\left\{x_{n}\right\}$ generated by

$$
x_{n+1}=S\left[I-\gamma A^{*}(I-T) A\right] x_{n}
$$

converges weakly to a solution of $\operatorname{SFFP}(5)$.

Proposition 12 (see [2]). Let $G$ be a $\alpha$-averaged self-mapping on $\mathscr{H}$ with $\operatorname{Fix}(G) \neq \emptyset$ and assume that $\left\{\alpha_{n}\right\}$ is a sequence in $[0,1 / \alpha]$ such that

$$
\sum_{n=1}^{\infty} \alpha_{n}\left(\frac{1}{\alpha}-\alpha_{n}\right)=\infty
$$

Then, for any $x_{1} \in \mathscr{H}$, the sequence $\left\{x_{n}\right\}$ generated by the Mann's algorithm

$$
x_{n+1}=\left(1-\alpha_{n}\right) x_{n}+\alpha_{n} G x_{n}
$$

converges weakly to a fixed point of $G$.
Applying Propositions 8, 9, and 12, we have the following result.

Theorem 13. Assume that $\operatorname{SFFP(5)}$ has a solution and $\gamma \in$ $\left(0,2 /\|A\|^{2}\right)$. Let $\left\{\alpha_{n}\right\}$ be a sequence in $\left[0,4 /\left(2+\gamma\|A\|^{2}\right)\right]$ with

$$
\sum_{n=1}^{\infty} \alpha_{n}\left(\frac{4}{2+\|A\|^{2}}-\alpha_{n}\right)=\infty
$$

Then, for any $x_{1} \in \mathscr{H}$, the sequence $\left\{x_{n}\right\}$ generated by the Mann's algorithm

$$
x_{n+1}=\left(1-\alpha_{n}\right) x_{n}+\alpha_{n} S\left[I-\gamma A^{*}(I-T) A\right] x_{n}
$$

converges weakly to a solution of $\operatorname{SFFP(5).~}$

\section{Strong Convergence Theorems}

In this section, we devise two algorithms, one for $\operatorname{SFFP}(16)$ and the other for $\operatorname{SFFP}(5)$. We deal with $\operatorname{SFFP}(16)$ firstly. To begin with, we need a lemma.

Lemma 14. For any $\gamma \in\left(0,2 /\|A\|^{2}\right)$ and all $x, y \in \mathscr{H}_{1}$, one has

$$
\begin{gathered}
\left\|\left[I-\gamma A^{*}(I-T) A\right] x-\left[I-\gamma A^{*}(I-T) A\right] y\right\|^{2} \\
\leq\|x-y\|^{2}-\left(2 \gamma-\gamma^{2}\|A\|^{2}\right) \\
\quad \times\|(I-T) A x-(I-T) A y\|^{2} .
\end{gathered}
$$

Proof. Since $T$ is firmly nonexpansive, so is $I-T$. Hence, for all $x, y \in \mathscr{H}_{1}$, we have

$$
\begin{aligned}
& \|(I-T) A x-(I-T) A y\|^{2} \\
& \quad \leq\langle A x-A y,(I-T) A x-(I-T) A y\rangle .
\end{aligned}
$$

Consequently,

$$
\begin{aligned}
\|[ & \left.-\gamma A^{*}(I-T) A\right] x-\left[I-\gamma A^{*}(I-T) A\right] y \|^{2} \\
= & \|x-y\|^{2}-2 \gamma \\
& \times\left\langle x-y, A^{*}(I-T) A x-A^{*}(I-T) A y\right\rangle \\
& +\gamma^{2}\left\|A^{*}(I-T) A x-A^{*}(I-T) A y\right\|^{2} \\
= & \|x-y\|^{2}-2 \gamma \\
& \times\langle A x-A y,(I-T) A x-(I-T) A y\rangle \\
& +\gamma^{2}\left\|A^{*}(I-T) A x-A^{*}(I-T) A y\right\|^{2} \\
\leq & \|x-y\|^{2}-2 \gamma\|(I-T) A x-(I-T) A y\|^{2} \\
& +\gamma^{2}\|A\|^{2}\|(I-T) A x-(I-T) A y\|^{2} \\
= & \|x-y\|^{2}-\left(2 \gamma-\gamma^{2}\|A\|^{2}\right) \\
& \times\|(I-T) A x-(I-T) A y\|^{2} .
\end{aligned}
$$


Theorem 15. Let $\left\{a_{n}\right\},\left\{b_{n}\right\},\left\{c_{n}\right\}$, and $\left\{d_{n}\right\}$ be sequences in $[0,1]$ with $a_{n}+b_{n}+c_{n}+d_{n}=1$ and $a_{n} \in(0,1)$ for all $n \in \mathbb{N}$. Let $\left\{\gamma_{n}\right\}$ be a sequence in $\left(0,2 /\|A\|^{2}\right)$ and let $\left\{e_{n}\right\}$ be a bounded sequence in $\mathscr{H}_{1}$. Suppose that the solution set $\Omega$ of SFFP $(16)$ is nonempty. For any $u \in \mathscr{H}_{1}$, start with any $x_{1} \in \mathscr{H}_{1}$ and define a sequence $\left\{x_{n}\right\}$ by

$$
x_{n+1}=a_{n} u+b_{n} x_{n}+c_{n} S_{n}\left[I-\gamma_{n} A^{*}\left(I-T_{n}\right) A\right] x_{n}+d_{n} e_{n} .
$$

Then the sequence $\left\{x_{n}\right\}$ converges strongly to $P_{\Omega} u$ provided that the following conditions are satisfied:

(i) $\lim _{n \rightarrow \infty} a_{n}=\lim _{n \rightarrow \infty}\left(d_{n} / a_{n}\right)=0, \sum_{n=1}^{\infty} a_{n}=\infty$, $\sum_{n=1}^{\infty} d_{n}<\infty$;

(ii) $\lim _{n \rightarrow \infty} \inf c_{n}\left(2 \gamma_{n}-\gamma_{n}^{2}\|A\|^{2}\right)>0, \lim _{n \rightarrow \infty} \inf b_{n} c_{n}>$ 0 ;

(iii) there are two nonnegative real-valued functions $\kappa_{1}$ and $\kappa_{2}$ on $\mathbb{N}$ with

$$
\begin{gathered}
\left\|S_{m} x-x\right\| \leq \kappa_{1}(m)\left\|S_{n} x-x\right\|, \\
\forall m \in \mathbb{N}, \quad \forall n \geq m, \forall x \in \mathscr{H}_{1}, \\
\left\|T_{m} y-y\right\| \leq \kappa_{2}(m)\left\|T_{n} y-y\right\|, \\
\forall m \in \mathbb{N}, \quad \forall n \geq m, \forall y \in \mathscr{H}_{2} .
\end{gathered}
$$

Proof. Put $p=P_{\Omega} u$. For simplicity, put $G_{n}=S_{n}\left(I-\gamma_{n} A^{*}(I-\right.$ $\left.T_{n}\right) A$ ). In view of Proposition $9, G_{n}$ is nonexpansive, so

$$
\begin{aligned}
& \left\|x_{n+1}-p\right\| \\
& =\| a_{n}(u-p)+b_{n}\left(x_{n}-p\right) \\
& \quad+c_{n}\left(G_{n} x_{n}-p\right)+d_{n}\left(e_{n}-p\right) \| \\
& \leq a_{n}\|u-p\|+\left(b_{n}+c_{n}\right) \\
& \quad \times\left\|x_{n}-p\right\|+d_{n}\left\|e_{n}-p\right\|,
\end{aligned}
$$

from which follows that $\left\{x_{n}\right\}$ is a bounded sequence. Taking into account Lemma 3, we get

$$
\begin{aligned}
& \left\|x_{n+1}-p\right\|^{2} \\
& =\| a_{n}(u-p)+b_{n}\left(x_{n}-p\right) \\
& \quad+c_{n}\left(G_{n} x_{n}-p\right)+d_{n}\left(e_{n}-p\right) \|^{2} \\
& \leq\left\|b_{n}\left(x_{n}-p\right)+c_{n}\left(G_{n} x_{n}-p\right)+d_{n}\left(e_{n}-p\right)\right\|^{2} \\
& \quad+2 a_{n}\left\langle u-p, x_{n+1}-p\right\rangle \\
& =\left(1-a_{n}\right)^{2} \| \frac{b_{n}}{1-a_{n}}\left(x_{n}-p\right) \\
& \quad+\frac{c_{n}}{1-a_{n}}\left(G_{n} x_{n}-p\right) \\
& \quad+\frac{d_{n}}{1-a_{n}}\left(e_{n}-p\right) \|^{2}
\end{aligned}
$$

$$
\begin{aligned}
& +2 a_{n}\left\langle u-p, x_{n+1}-p\right\rangle \\
& \leq\left(1-a_{n}\right)^{2}\left(\frac{b_{n}}{1-a_{n}}\left\|x_{n}-p\right\|^{2}+\frac{c_{n}}{1-a_{n}}\right. \\
& \left.\quad \times\left\|G_{n} x_{n}-p\right\|^{2}+\frac{d_{n}}{1-a_{n}}\left\|e_{n}-p\right\|^{2}\right) \\
& -b_{n} c_{n}\left\|x_{n}-G_{n} x_{n}\right\|^{2}+2 a_{n}\left\langle u-p, x_{n+1}-p\right\rangle \\
& \leq b_{n}\left\|x_{n}-p\right\|^{2}+c_{n}\left\|G_{n} x_{n}-p\right\|^{2} \\
& +d_{n}\left\|e_{n}-p\right\|^{2}-b_{n} c_{n}\left\|x_{n}-G_{n} x_{n}\right\|^{2} \\
& +2 a_{n}\left\langle u-p, x_{n+1}-p\right\rangle .
\end{aligned}
$$

Meanwhile, we have by Lemma 14 that

$$
\begin{aligned}
& \left\|G_{n} x_{n}-p\right\|^{2} \\
& =\| S_{n}\left(I-\gamma_{n} A^{*}\left(I-T_{n}\right) A\right) x_{n} \\
& \quad \quad-S_{n}\left(I-\gamma_{n} A^{*}\left(I-T_{n}\right) A\right) p \|^{2} \\
& \leq \|\left(I-\gamma_{n} A^{*}\left(I-T_{n}\right) A\right) x_{n} \\
& \quad-\left(I-\gamma_{n} A^{*}\left(I-T_{n}\right) A\right) p \|^{2} \\
& \leq\left\|x_{n}-p\right\|^{2}-\left(2 \gamma_{n}-\gamma_{n}^{2}\|A\|^{2}\right) \\
& \quad \times\left\|\left(I-T_{n}\right) A x_{n}-\left(I-T_{n}\right) A p\right\|^{2} .
\end{aligned}
$$

Therefore, we deduce that

$$
\begin{aligned}
& \left\|x_{n+1}-p\right\|^{2} \\
& \leq b_{n}\left\|x_{n}-p\right\|^{2} \\
& +c_{n}\left[\left\|x_{n}-p\right\|^{2}-\left(2 \gamma_{n}-\gamma_{n}^{2}\|A\|^{2}\right)\right. \\
& \left.\quad \times\left\|\left(I-T_{n}\right) A x_{n}-\left(I-T_{n}\right) A p\right\|^{2}\right] \\
& +d_{n}\left\|e_{n}-p\right\|^{2}-b_{n} c_{n}\left\|x_{n}-G_{n} x_{n}\right\|^{2} \\
& +2 a_{n}\left\langle u-p, x_{n+1}-p\right\rangle \\
& =\left(b_{n}+c_{n}\right)\left\|x_{n}-p\right\|^{2}+d_{n}\left\|e_{n}-p\right\|^{2} \\
& +2 a_{n}\left\langle u-p, x_{n+1}-p\right\rangle \\
& -c_{n}\left(2 \gamma_{n}-\gamma_{n}^{2}\|A\|^{2}\right)\left\|\left(I-T_{n}\right) A x_{n}\right\|^{2} \\
& -b_{n} c_{n}\left\|x_{n}-G_{n} x_{n}\right\|^{2} .
\end{aligned}
$$

We now carry on with the proof by considering the following two cases: (I) $\left\{\left\|x_{n}-p\right\|\right\}$ is eventually decreasing and (II) $\left\{\| x_{n}-\right.$ $p \|\}$ is not eventually decreasing.

Case I. Suppose that $\left\{\left\|x_{n}-p\right\|\right\}$ is eventually decreasing; that is, there is $n_{0} \in \mathbb{N}$ such that $\left\{\left\|x_{n}-p\right\|\right\}_{n \geq n_{0}}$ is decreasing. In this 
case, $\lim _{n \rightarrow \infty}\left\|x_{n}-p\right\|$ exists in $\mathbb{R}$. From inequality (52) we have

$$
\begin{aligned}
c_{n}\left(2 \gamma_{n}-\gamma_{n}^{2}\|A\|^{2}\right)\left\|\left(I-T_{n}\right) A x_{n}\right\|^{2} \\
\quad+b_{n} c_{n}\left\|x_{n}-G_{n} x_{n}\right\|^{2} \\
\leq\left(b_{n}+c_{n}\right)\left\|x_{n}-p\right\|^{2}+d_{n}\left\|e_{n}-p\right\|^{2} \\
\quad+2 a_{n}\left\langle u-p, x_{n+1}-p\right\rangle-\left\|x_{n+1}-p\right\|^{2},
\end{aligned}
$$

which together with the boundedness of $\left\{x_{n}\right\}$ and conditions (i) and (ii) implies

$$
\begin{gathered}
\lim _{n \rightarrow \infty}\left\|x_{n}-G_{n} x_{n}\right\|=0, \\
\lim _{n \rightarrow \infty}\left\|A x_{n}-T_{n} A x_{n}\right\|=0 .
\end{gathered}
$$

Then, an application of condition (iii) follows that for all $m \in$ $\mathbb{N}$,

$$
\lim _{n \rightarrow \infty}\left\|x_{n}-G_{m} x_{n}\right\|=\lim _{n \rightarrow \infty}\left\|A x_{n}-T_{m} A x_{n}\right\|=0 .
$$

Since $\left\{x_{n}\right\}$ is bounded, it has a subsequence $\left\{x_{n_{k}}\right\}$ such that $\left\{x_{n_{k}}\right\}$ converges weakly to some $z \in \mathscr{H}$ and

$$
\begin{gathered}
\limsup _{n \rightarrow \infty}\left\langle u-p, x_{n+1}-p\right\rangle \\
\quad=\lim _{k \rightarrow \infty}\left\langle u-p, x_{n_{k}}-p\right\rangle \\
\quad=\langle u-p, z-p\rangle \leq 0,
\end{gathered}
$$

where the last inequality follows from (24) since $z \in \Omega$ by Lemma 4. Choose $M>0$ so that $\sup \left\{\left\|e_{n}-p\right\|^{2}+2 \| u-\right.$ $\left.p\|\| x_{n+1}-p \|: n \in \mathbb{N}\right\} \leq M$. From (52) we have

$$
\begin{aligned}
\| x_{n+1} & -p \|^{2} \\
\leq & \left(1-\left(a_{n}+d_{n}\right)\right)\left\|x_{n}-p\right\|^{2} \\
& +\left(a_{n}+d_{n}\right) \cdot 2\left\langle u-p, x_{n+1}-p\right\rangle \\
& +d_{n}\left(\left\|e_{n}-p\right\|^{2}+2\|u-p\|\left\|x_{n+1}-p\right\|\right) \\
\leq & \left(1-\left(a_{n}+d_{n}\right)\right)\left\|x_{n}-p\right\|^{2} \\
& +\left(a_{n}+d_{n}\right) \cdot 2\left\langle u-p, x_{n+1}-p\right\rangle+d_{n} M .
\end{aligned}
$$

Accordingly, because of (56) and condition (i), we can apply Lemma 5 to inequality (57) with $s_{n}=\left\|x_{n}-p\right\|^{2}, \alpha_{n}=a_{n}+b_{n}$, $\mu_{n}=2\left\langle u-p, x_{n+1}-p\right\rangle$, and $\nu_{n}=d_{n} M$ to conclude that

$$
\lim _{n \rightarrow \infty} x_{n}=p .
$$

Case II. Suppose that $\left\{\left\|x_{n}-p\right\|\right\}$ is not eventually decreasing. In this case, by Lemma 6, there exists a nondecreasing sequence $\left\{m_{k}\right\}$ in $\mathbb{N}$ such that $m_{k} \rightarrow \infty$ and

$$
\begin{aligned}
& \max \left\{\left\|x_{m_{k}}-p\right\|,\left\|x_{k}-p\right\|\right\} \\
& \leq\left\|x_{m_{k}+1}-p\right\|, \quad \forall k \in \mathbb{N} .
\end{aligned}
$$

Then, it follows from (52) and (59) that

$$
\begin{aligned}
\| x_{m_{k}} & -p \|^{2} \\
\leq & \left\|x_{m_{k}+1}-p\right\|^{2} \\
\leq & \left(b_{m_{k}}+c_{m_{k}}\right)\left\|x_{m_{k}}-p\right\|^{2} \\
& +d_{m_{k}}\left\|e_{m_{k}}-p\right\|^{2} \\
& +2 a_{m_{k}}\left\langle u-p, x_{m_{k}+1}-p\right\rangle \\
& -c_{m_{k}}\left(2 \gamma_{m_{k}}-\gamma_{m_{k}}^{2}\|A\|^{2}\right) \\
& \times\left\|\left(I-T_{m_{k}}\right) A x_{m_{k}}\right\|^{2}-b_{m_{k}} c_{m_{k}}\left\|x_{m_{k}}-G_{m_{k}} x_{m_{k}}\right\|^{2} .
\end{aligned}
$$

Therefore,

$$
\begin{aligned}
0 \leq & c_{m_{k}}\left(2 \gamma_{m_{k}}+\gamma_{m_{k}}^{2}\|A\|^{2}\right)\left\|\left(I-T_{m_{k}}\right) A x_{m_{k}}\right\|^{2} \\
& +b_{m_{k}} c_{m_{k}}\left\|x_{m_{k}}-G_{m_{k}} x_{m_{k}}\right\|^{2} \\
\leq & -\left(1-\left(b_{m_{k}}+c_{m_{k}}\right)\right)\left\|x_{m_{k}}-p\right\|^{2} \\
& +d_{m_{k}}\left\|e_{m_{k}}-p\right\|^{2}+2 a_{m_{k}}\left\langle u-p, x_{m_{k}+1}-p\right\rangle \\
= & -\left(a_{m_{k}}+d_{m_{k}}\right)\left\|x_{m_{k}}-p\right\|^{2} \\
& +d_{m_{k}}\left\|e_{m_{k}}-p\right\|^{2}+2 a_{m_{k}}\left\langle u-p, x_{m_{k}+1}-p\right\rangle,
\end{aligned}
$$

and then proceeding just as in the proof in Case I, we obtain

$$
\begin{aligned}
& \lim _{k \rightarrow \infty}\left\|x_{m_{k}}-G_{m_{k}} x_{m_{k}}\right\| \\
& =\lim _{k \rightarrow \infty}\left\|A x_{m_{k}}-T_{m_{k}} A x_{m_{k}}\right\|=0,
\end{aligned}
$$

which in conjunction with condition (iii) shows that for all $m_{j}$

$$
\begin{aligned}
& \lim _{k \rightarrow \infty}\left\|x_{m_{k}}-G_{m_{j}} x_{m_{k}}\right\| \\
& =\lim _{k \rightarrow \infty}\left\|A x_{m_{k}}-T_{m_{j}} A x_{m_{k}}\right\|=0,
\end{aligned}
$$

and then follows that

$$
\limsup _{k \rightarrow \infty}\left\langle u-p, x_{m_{k}+1}-p\right\rangle \leq 0
$$

From (60) we have

$$
\begin{aligned}
& \left(1-\left(b_{m_{k}}+c_{m_{k}}\right)\right)\left\|x_{m_{k}}-p\right\|^{2} \\
& \quad \leq d_{m_{k}}\left\|e_{m_{k}}-p\right\|^{2}+2 a_{m_{k}}\left\langle u-p, x_{m_{k}+1}-p\right\rangle,
\end{aligned}
$$


and thus,

$$
\begin{aligned}
\left\|x_{m_{k}}-p\right\|^{2} \leq & \frac{d_{m_{k}}}{a_{m_{k}}+d_{m_{k}}}\left\|e_{m_{k}}-p\right\|^{2} \\
& +\frac{2 a_{m_{k}}}{a_{m_{k}}+d_{m_{k}}}\left\langle u-p, x_{m_{k}+1}-p\right\rangle \\
\leq & \frac{d_{m_{k}}}{a_{m_{k}}}\left\|e_{m_{k}}-p\right\|^{2} \\
& +2\left\langle u-p, x_{m_{k}+1}-p\right\rangle .
\end{aligned}
$$

Letting $k \rightarrow \infty$ and using (64) and condition (i), we obtain

$$
\lim _{k \rightarrow \infty}\left\|x_{m_{k}}-p\right\|=0
$$

Also, since

$$
\begin{aligned}
& \left\|x_{m_{k}+1}-x_{m_{k}}\right\| \\
& \quad \leq a_{m_{k}}\left\|u-x_{m_{k}}\right\|+c_{m_{k}}\left\|G_{m_{k}} x_{m_{k}}-x_{m_{k}}\right\| \\
& \quad+d_{m_{k}}\left\|e_{m_{k}}-x_{m_{k}}\right\|,
\end{aligned}
$$

which together with (62) and condition (i) implies that $\lim _{k \rightarrow \infty}\left\|x_{m_{k}+1}-x_{m_{k}}\right\|=0$, and so

$$
\lim _{k \rightarrow \infty}\left\|x_{m_{k}+1}-p\right\|=0
$$

by virtue of (67). Consequently, we conclude that $\lim _{k \rightarrow \infty}\left\|x_{k}-p\right\|=0$ via (59) and (69). This completes the proof.

This theorem says that the sequence $\left\{x_{n}\right\}$ converges strongly to a point of $\Omega$ which is the nearest to $u$. In particular, if $u$ is taken to be 0 , then the limit point $v$ of the sequence $\left\{x_{n}\right\}$ is the unique minimum solution of $\operatorname{SFFP}(16)$.

Corollary 16. Let $\left\{a_{n}\right\},\left\{b_{n}\right\}$, and $\left\{c_{n}\right\}$ be sequences in $[0,1]$ with $a_{n}+b_{n}+c_{n}=1$ and $a_{n} \in(0,1)$ for all $n \in \mathbb{N}$. Let $\left\{\gamma_{n}\right\}$ be a sequence in $\left(0,2 /\|A\|^{2}\right)$ and let $\left\{e_{n}\right\}$ be a bounded sequence in $\mathscr{H}_{1}$. Suppose that the solution set $\Omega$ of $\operatorname{SFFP}(16)$ is nonempty. For any $u \in \mathscr{H}_{1}$, start with any $x_{1} \in \mathscr{H}_{1}$ and define a sequence $\left\{x_{n}\right\}$ by

$$
x_{n+1}=a_{n} u+b_{n} x_{n}+c_{n} S_{n}\left[I-\gamma_{n} A^{*}\left(I-T_{n}\right) A\right] x_{n}+e_{n} .
$$

Then, the sequence $\left\{x_{n}\right\}$ converges strongly to $P_{\Omega} u$ provided that the following conditions are satisfied:

(i) $\lim _{n \rightarrow \infty} a_{n}=\lim _{n \rightarrow \infty}\left(d_{n} / a_{n}\right)=0, \sum_{n=1}^{\infty} a_{n}=\infty$, $\sum_{n=1}^{\infty} d_{n}<\infty$

(ii) $\lim _{n \rightarrow \infty} \inf c_{n}\left(2 \gamma_{n}-\gamma_{n}^{2}\|A\|^{2}\right)>0, \lim _{n \rightarrow \infty} \inf b_{n} c_{n}>$ 0 ; (iii) there are two nonnegative real-valued functions $\kappa_{1}$ and $\kappa_{2}$ on $\mathbb{N}$ with

$$
\begin{gathered}
\left\|S_{m} x-x\right\| \leq \kappa_{1}(m)\left\|S_{n} x-x\right\|, \\
\forall m \in \mathbb{N}, \forall n \geq m, \forall x \in \mathscr{H}_{1}, \\
\left\|T_{m} y-y\right\| \leq \kappa_{2}(m)\left\|T_{n} y-y\right\|, \\
\forall m \in \mathbb{N}, \quad \forall n \geq m, \forall y \in \mathscr{H}_{2} ;
\end{gathered}
$$

(iv) either $\lim _{n \rightarrow \infty}\left(\left\|e_{n}\right\| / a_{n}\right)=0$ or $\sum_{n=1}^{\infty}\left\|e_{n}\right\|<\infty$.

Proof. Put $p=P_{\Omega} u$ and $G_{n}=S_{n}\left[I-\gamma_{n} A^{*}\left(I-T_{n}\right) A\right]$. Let $z_{1}=x_{1}$ and define a sequence $\left\{z_{n}\right\}$ iteratively by

$$
z_{n+1}=a_{n} u+b_{n} z_{n}+c_{n} G_{n} z_{n} .
$$

We have $\lim _{n \rightarrow \infty} z_{n}=p$ by Theorem 15. Since

$$
\begin{aligned}
\left\|x_{n+1}-z_{n+1}\right\| \leq & b_{n}\left\|x_{n}-z_{n}\right\| \\
& +c_{n}\left\|G_{n} x_{n}-G_{n} z_{n}\right\|+\left\|e_{n}\right\| \\
\leq & \left(b_{n}+c_{n}\right)\left\|x_{n}-z_{n}\right\|+\left\|e_{n}\right\| \\
= & \left(1-a_{n}\right)\left\|x_{n}-z_{n}\right\|+\left\|e_{n}\right\|,
\end{aligned}
$$

the $\operatorname{limit}_{n \rightarrow \infty}\left\|x_{n}-z_{n}\right\|=0$ follows by applying Lemma 5 to (74), and thus,

$$
\lim _{n \rightarrow \infty} x_{n}=p
$$

If the sequence $\left\{S_{n}\right\}$ (resp., $\left\{T_{n}\right\}$ ) of firmly nonexpansive mappings consists of a single mapping $S$ (resp., $T$ ), then $\left\{S_{n}\right\}$ and $\left\{T_{n}\right\}$ obviously verify condition (iii), and hence, we have the following corollary.

Corollary 17. Let $\left\{a_{n}\right\},\left\{b_{n}\right\},\left\{c_{n}\right\}$, and $\left\{d_{n}\right\}$ be sequences in $[0,1]$ with $a_{n}+b_{n}+c_{n}+d_{n}=1$ and $a_{n} \in(0,1)$ for all $n \in \mathbb{N}$. Let $\left\{\gamma_{n}\right\}$ be a sequence in $\left(0,2 /\|A\|^{2}\right)$ and let $\left\{e_{n}\right\}$ be a bounded sequences in $\mathscr{H}_{1}$. Assume that the solution set $\Omega$ of SFFP(5) is nonempty. For any $u \in \mathscr{H}_{1}$, start with an arbitrary $x_{1} \in \mathscr{H}_{1}$ and define the sequence $\left\{x_{n}\right\}$ by

$$
x_{n+1}=a_{n} u+b_{n} x_{n}+c_{n} S\left[I-\gamma_{n} A^{*}(I-T) A\right] x_{n}+d_{n} e_{n} .
$$

Then, $\left\{x_{n}\right\}$ converges strongly to $P_{\Omega} u$ provided that the following conditions are satisfied:

(i) $\lim _{n \rightarrow \infty} a_{n}=\lim _{n \rightarrow \infty}\left(d_{n} / a_{n}\right)=0, \sum_{n=1}^{\infty} a_{n}=\infty$, $\sum_{n=1}^{\infty} d_{n}<\infty$;

(ii) $\lim _{n \rightarrow \infty} \inf c_{n}\left(2 \gamma_{n}-\gamma_{n}^{2}\|A\|^{2}\right)>0, \lim _{n \rightarrow \infty} \inf b_{n} c_{n}>$ 0 .

When the sequence $\left\{\gamma_{n}\right\}$ is taken to be a constant $\gamma \in$ $\left(0,2 /\|A\|^{2}\right)$, then because $S\left[I-\gamma_{n} A^{*}(I-T) A\right]$ is an averaged mapping, we can apply Corollary 3.4 of Huang and Hong [26] to obtain the following result. 
Theorem 18. Let $\left\{a_{n}\right\},\left\{b_{n}\right\},\left\{c_{n}\right\}$, and $\left\{d_{n}\right\}$ be sequences in $[0,1]$ with $a_{n}+b_{n}+c_{n}+d_{n}=1$ and $a_{n} \in(0,1)$ for all $n \in \mathbb{N}$. Suppose that $\gamma \in\left(0,2 /\|A\|^{2}\right)$ and suppose that $\left\{e_{n}\right\}$ is a bounded sequence in $\mathscr{H}_{1}$. Assume that the solution set $\Omega$ of $\operatorname{SFFP}(5)$ is nonempty. For any $u \in \mathscr{H}_{1}$, start with an arbitrary $x_{1} \in \mathscr{H}_{1}$ and define the sequence $\left\{x_{n}\right\}$ by

$$
x_{n+1}=a_{n} u+b_{n} x_{n}+c_{n} S\left[I-\gamma A^{*}(I-T) A\right] x_{n}+d_{n} e_{n} .
$$

Then, $\left\{x_{n}\right\}$ converges strongly to $P_{\Omega} u$ provided that the following conditions are satisfied:

(i) $\lim _{n \rightarrow \infty} a_{n}=\lim _{n \rightarrow \infty}\left(d_{n} / a_{n}\right)=0, \sum_{n=1}^{\infty} a_{n}=\infty$, $\sum_{n=1}^{\infty} d_{n}<\infty$

(ii) $\lim _{n \rightarrow \infty} \inf b_{n}>0, \lim _{n \rightarrow \infty} \inf c_{n}>0$.

Since both condition (ii) of Corollary 17 and Theorem 18 are equivalent provided that $\gamma_{n}=\gamma$ for every $n \in \mathbb{N}$, Theorem 18 also follows from Corollary 17.

We now turn to $\operatorname{SFFP}(5)$ for another algorithm, which essentially follows the argument of Wang and $\mathrm{Xu}$ [27]. For the sake of completeness, we still give a detailed proof.

Theorem 19. Let $\left\{a_{n}\right\}$ be a sequence in $(0,1)$. Suppose that $\gamma \in$ $\left(0,2 /\|A\|^{2}\right)$ and assume that the solution set $\Omega$ of $\operatorname{SFFP}(5)$ is nonempty. Start with any $x_{1} \in \mathscr{H}_{1}$ and define a sequence $\left\{x_{n}\right\}$ by

$$
x_{n+1}=S\left[\left(1-a_{n}\right)\left(I-\gamma A^{*}(I-T) A\right)\right] x_{n} .
$$

Then, the sequence $\left\{x_{n}\right\}$ converges strongly to the minimum norm solution of SFFP(5) provided that the following conditions are satisfied:

(i) $\lim _{n \rightarrow \infty} a_{n}=0$;

(ii) $\sum_{n=1}^{\infty} a_{n}=\infty$;

(iii) either $\sum_{n=1}^{\infty}\left|a_{n+1}-a_{n}\right|<\infty$ or $\lim _{n \rightarrow \infty}\left(\mid a_{n+1}-\right.$ $\left.a_{n} \mid / a_{n}\right)=0$.

Proof. Put $U=I-\gamma A^{*}(I-T) A, G=S U$, and $G_{n}=S[(1-$ $\left.\left.a_{n}\right)\right] U$ for all $n \in \mathbb{N}$. Then,

$$
\begin{gathered}
x_{n+1}=G_{n} x_{n}=S\left[\left(1-a_{n}\right) U\right] x_{n}, \\
\left\|G_{n} x-G_{n} y\right\| \leq\left(1-a_{n}\right)\|x-y\|, \quad \forall x, y \in \mathscr{H}_{1} .
\end{gathered}
$$

Take $p \in \Omega$. From Proposition 9, we have

$$
\begin{aligned}
\left\|G_{n} p-p\right\| & =\left\|S\left[\left(1-a_{n}\right) U\right] p-S U p\right\| \\
& \leq\left\|\left(1-a_{n}\right) U p-U p\right\| \\
& =a_{n}\|U p\|=a_{n}\|p\| .
\end{aligned}
$$

Hence,

$$
\begin{aligned}
\left\|x_{n+1}-p\right\| & =\left\|G_{n} x_{n}-p\right\| \\
& \leq\left\|G_{n} x_{n}-G_{n} p\right\|+\left\|G_{n} p-p\right\| \\
& \leq\left(1-a_{n}\right)\left\|x_{n}-p\right\|+a_{n}\|p\|,
\end{aligned}
$$

from which follows that $\left\{x_{n}\right\}$ is bounded and so is $\left\{U x_{n}\right\}$. Choose $M>0$ so that $\left\|U x_{n}\right\| \leq M$ for all $n \in \mathbb{N}$. We have

$$
\begin{aligned}
\left\|x_{n+1}-x_{n}\right\|= & \left\|G_{n} x_{n}-G_{n-1} x_{n-1}\right\| \\
\leq & \left\|G_{n} x_{n}-G_{n} x_{n-1}\right\| \\
& +\left\|G_{n} x_{n-1}-G_{n-1} x_{n-1}\right\| \\
= & \left(1-a_{n}\right)\left\|x_{n}-x_{n-1}\right\| \\
& +\| S\left[\left(1-a_{n}\right) U x_{n-1}\right] \\
& \quad-S\left[\left(1-a_{n-1}\right) U x_{n-1}\right] \| \\
\leq & \left(1-a_{n}\right)\left\|x_{n}-x_{n-1}\right\| \\
& +\|\left(1-a_{n}\right) U x_{n-1} \\
& \quad-\left(1-a_{n-1}\right) U x_{n-1} \| \\
= & \left(1-a_{n}\right)\left\|x_{n}-x_{n-1}\right\| \\
& +\left|a_{n}-a_{n-1}\right|\left\|U x_{n-1}\right\| \\
\leq & \left(1-a_{n}\right)\left\|x_{n}-x_{n-1}\right\| \\
& +M\left|a_{n}-a_{n-1}\right| .
\end{aligned}
$$

In view of conditions (i), (ii), and (iii), we can apply Lemma 5 to $(82)$ to get

$$
\lim _{n \rightarrow \infty}\left\|x_{n+1}-x_{n}\right\|=0
$$

and then from

$$
\begin{aligned}
\left\|x_{n}-G x_{n}\right\| \leq & \left\|x_{n}-x_{n+1}\right\|+\left\|G_{n} x_{n}-G x_{n}\right\| \\
\leq & \left\|x_{n}-x_{n+1}\right\| \\
& \quad+\left\|\left(1-a_{n}\right) U x_{n}-U x_{n}\right\| \\
\leq & \left\|x_{n}-x_{n+1}\right\|+M\left\|U x_{n}\right\|,
\end{aligned}
$$

we see that

$$
\lim _{n \rightarrow \infty}\left\|x_{n}-T x_{n}\right\|=0
$$

Consequently, the demiclosedness principle ensures that each weak limit point of $\left\{x_{n}\right\}$ is a fixed point of the averaged mapping $S U$. And then we conclude from Proposition 9 that each weak limit point of $\left\{x_{n}\right\}$ lies in $\Omega$.

Let $\widehat{x}$ be the minimum norm element of $\Omega$; that is, $\widehat{x}=$ $P_{\Omega}(0)$. We shall show that $\left\{x_{n}\right\}$ converges strongly to $\widehat{x}$. To see 
this, we compute $\left\|x_{n+1}-\widehat{x}\right\|^{2}$ as follows:

$$
\begin{aligned}
&\left\|x_{n+1}-\hat{x}\right\|^{2} \\
&=\left\|S\left[\left(1-a_{n}\right) U x_{n}\right]-S U \hat{x}\right\|^{2} \\
& \leq\left\|\left(1-a_{n}\right) U x_{n}-U \widehat{x}\right\|^{2} \\
&=\left\|\left(1-a_{n}\right) U x_{n}-\hat{x}\right\|^{2} \\
&=\left\|\left(1-a_{n}\right)\left(U x_{n}-\widehat{x}\right)-a_{n} \widehat{x}\right\|^{2} \\
&=\left(1-a_{n}\right)^{2}\left\|U x_{n}-\widehat{x}\right\|^{2} \\
&+2 a_{n}\left(1-a_{n}\right)\left\langle U x_{n}-\widehat{x},-\widehat{x}\right\rangle+a_{n}^{2}\|\widehat{x}\|^{2} \\
& \leq\left(1-a_{n}\right)\left\|x_{n}-\widehat{x}\right\|^{2} \\
&+a_{n}\left[2\left(1-a_{n}\right)\left\langle U x_{n}-\widehat{x},-\widehat{x}\right\rangle+a_{n}\|\widehat{x}\|^{2}\right] .
\end{aligned}
$$

If $\lim \sup _{n \rightarrow \infty} 2\left(1-a_{n}\right)\left\langle U x_{n}-\widehat{x},-\widehat{x}\right\rangle+a_{n}\|\widehat{x}\|^{2} \leq 0$, then an application of Lemma 5 to (86) yields that $\lim _{n \rightarrow \infty} x_{n}=$ $\widehat{x}$. Hence, to complete the proof, it suffices to show that $\lim \sup _{n \rightarrow \infty} 2\left(1-a_{n}\right)\left\langle U x_{n}-\widehat{x},-\widehat{x}\right\rangle+a_{n}\|\widehat{x}\|^{2} \leq 0$. For this, taking into account Proposition 8 , we can write $U=(1-\beta) I+$ $\beta V$ for some $\beta \in(0,1)$ and some nonexpansive mapping $V$. Then, from

$$
\begin{aligned}
\left\|x_{n+1}-p\right\|^{2}= & \left\|S\left[\left(1-a_{n}\right) U\right] x_{n}-p\right\|^{2} \\
\leq & \left\|\left(1-a_{n}\right) U x_{n}-p\right\|^{2} \\
= & \left\|\left(1-a_{n}\right)\left(U x_{n}-p\right)-a_{n} p\right\|^{2} \\
\leq & \left(1-a_{n}\right)\left\|U x_{n}-p\right\|^{2}+a_{n}\|p\|^{2} \\
\leq & \|(1-\beta)\left(x_{n}-p\right) \\
& \quad+\beta\left(V x_{n}-p\right)\left\|^{2}+a_{n}\right\| p \|^{2} \\
= & (1-\beta)\left\|x_{n}-p\right\|^{2}+\beta\left\|V x_{n}-p\right\|^{2} \\
& -\beta(1-\beta)\left\|x_{n}-V x_{n}\right\|^{2}+a_{n}\|p\|^{2} \\
\leq & \left\|x_{n}-p\right\|^{2}-\beta(1-\beta)\left\|x_{n}-V x_{n}\right\|^{2} \\
& +a_{n}\|p\|^{2},
\end{aligned}
$$

we obtain

$$
\begin{aligned}
& \beta(1-\beta)\left\|x_{n}-V x_{n}\right\|^{2} \\
& \quad \leq\left\|x_{n}-p\right\|^{2}-\left\|x_{n+1}-p\right\|^{2}+a_{n}\|p\|^{2},
\end{aligned}
$$

which ensures that $\lim _{n \rightarrow \infty}\left\|x_{n}-V x_{n}\right\|=0$, and hence,

$$
\lim _{n \rightarrow \infty}\left\|x_{n}-U x_{n}\right\|=0
$$

once we note that $I-U=\beta(I-V)$. Since $\left\{x_{n}\right\}$ is bounded, we can take a subsequence $\left\{x_{n_{i}}\right\}$ so that it is weakly convergent to $x^{*} \in \Omega$ and

$$
\begin{aligned}
\limsup _{n \rightarrow \infty}\left\langle x_{n}-\hat{x},-\hat{x}\right\rangle & =\lim _{i \rightarrow \infty}\left\langle x_{n_{i}},-\hat{x}\right\rangle \\
& =\left\langle x^{*}-\widehat{x},-\hat{x}\right\rangle \leq 0,
\end{aligned}
$$

where the last inequality comes from the characterization inequality of a metric projection. Now, applying (89) and (90) to the equality

$$
\left\langle U x_{n}-\widehat{x},-\widehat{x}\right\rangle=\left\langle U x_{n}-x_{n},-\widehat{x}\right\rangle+\left\langle x_{n}-\widehat{x},-\widehat{x}\right\rangle,
$$

we obtain

$$
\limsup _{n \rightarrow \infty}\left\langle U x_{n}-\widehat{x},-\widehat{x}\right\rangle \leq 0 \text {, }
$$

and thus,

$$
\limsup _{n \rightarrow \infty} 2\left(1-a_{n}\right)\left\langle U x_{n}-\widehat{x},-\widehat{x}\right\rangle+a_{n}\|\widehat{x}\|^{2} \leq 0 .
$$

This completes the proof.

\section{Applications}

In this section, we shall apply the results in Section 4 to approximate zeros of maximal monotone operators and solutions of equilibrium problems.

Theorem 20. Suppose that $M$ and $N$ are two maximal monotone operators on $\mathscr{H}_{1}$ and $\mathscr{H}_{2}$, respectively, and suppose that $A: \mathscr{H}_{1} \rightarrow \mathscr{H}_{2}$ is a bounded linear operator with adjoint $A^{*}$. Suppose further that $\left\{a_{n}\right\},\left\{b_{n}\right\},\left\{c_{n}\right\}$, and $\left\{d_{n}\right\}$ are sequences in $[0,1]$ with $a_{n}+b_{n}+c_{n}+d_{n}=1$ and $a_{n} \in(0,1)$ for all $n \in \mathbb{N}$. Let $\left\{\alpha_{n}\right\}$ and $\left\{\beta_{n}\right\}$ be sequences in $(0, \infty),\left\{\gamma_{n}\right\}$ a sequence in $\left(0,2 /\|A\|^{2}\right)$, and $\left\{e_{n}\right\}$ a bounded sequence in $\mathscr{H}_{1}$. Assume that the solution set $\Omega$ of the problem

$$
\begin{gathered}
\text { find } x^{*} \in \mathscr{H}_{1} \\
\text { so that } x^{*} \in M^{-1} 0, \quad A x^{*} \in N^{-1} 0
\end{gathered}
$$

is nonempty. For any $u \in \mathscr{H}_{1}$, start with an arbitrary $x_{1} \in \mathscr{H}$ and define a sequence $\left\{x_{n}\right\}$ by

$$
\begin{aligned}
x_{n+1}= & a_{n} u+b_{n} x_{n}+c_{n} J_{\alpha_{n}}^{M}\left[I-\gamma_{n} A^{*}\left(I-J_{\beta_{n}}^{N}\right)\right] x_{n} \\
& +d_{n} e_{n} .
\end{aligned}
$$

Then, the sequence $\left\{x_{n}\right\}$ converges strongly to $P_{\Omega} u$ provided that the following conditions are satisfied: (i) $\lim _{n \rightarrow \infty} a_{n}=\lim _{n \rightarrow \infty}\left(d_{n} / a_{n}\right)=0, \sum_{n=1}^{\infty} a_{n}=\infty$,
$\sum_{n=1}^{\infty} d_{n}<\infty ;$

(ii) $\lim _{n \rightarrow \infty} \inf c_{n}\left(2 \gamma_{n}-\gamma_{n}^{2}\|A\|^{2}\right)>0, \lim _{n \rightarrow \infty} \inf b_{n} c_{n}>$ 0 ;

(iii) $\lim _{n \rightarrow \infty} \inf \alpha_{n}>0, \lim _{n \rightarrow \infty} \inf \beta_{n}>0$. 
Proof. For any $n \in \mathbb{N}$, letting $S_{n}=J_{\alpha_{n}}^{M}$ and $T_{n}=J_{\beta_{n}}^{N}$, then we have by Lemma 2(b) that $M^{-1} 0=\operatorname{Fix}\left(S_{n}\right)$ and $N^{-1} 0=$ $\operatorname{Fix}\left(T_{n}\right)$ for all $n \in \mathbb{N}$, and hence, as shown in Section 1, the problem (94) becomes SFFP(16). Since all the requirements of Theorem 15 are satisfied except condition (iii), we have to check this condition. Because $\liminf _{n \rightarrow \infty} \alpha_{n}=0$, $\lim _{\text {inf }}{ }_{n \rightarrow \infty} \beta_{n}=0$ by assumption, we may assume that there is $\tau \in(0,1)$ so that $\tau<\alpha_{n}$ and $\tau<\beta_{n}$ for all $n \in \mathbb{N}$. Let $\kappa_{1}(n)=2+\left(\alpha_{n} / \tau\right)$ and $\kappa_{2}(n)=2+\left(\beta_{n} / \tau\right)$. Then, by virtue of the resolvent identity and the nonexpansiveness of $J_{\alpha_{m}}^{M}$, one has for all $m \in \mathbb{N}$ that

$$
\begin{aligned}
\left\|J_{\alpha_{n}}^{M} x-J_{\alpha_{m}}^{M} x\right\| & =\left\|J_{\alpha_{m}}^{M}\left(\frac{\alpha_{m}}{\alpha_{n}} x+\left(1-\frac{\alpha_{m}}{\alpha_{n}}\right) J_{\alpha_{n}}^{M} x\right)-J_{\alpha_{m}}^{M} x\right\| \\
& \leq\left|1-\frac{\alpha_{m}}{\alpha_{n}}\right|\left\|J_{\alpha_{n}}^{M} x-x\right\| \\
& \leq\left(1+\frac{\alpha_{m}}{\alpha_{n}}\right)\left\|J_{\alpha_{n}}^{M} x-x\right\|,
\end{aligned}
$$

and thus,

$$
\begin{aligned}
\left\|J_{\alpha_{m}}^{M} x-x\right\| \leq & \left\|J_{\alpha_{m}}^{M} x-J_{\alpha_{n}}^{M} x\right\|+\left\|J_{\alpha_{n}}^{M} x-x\right\| \\
\leq & \left(1+\frac{\alpha_{m}}{\alpha_{n}}+1\right)\left\|J_{\alpha_{n}}^{M} x-x\right\| \\
\leq & \left(2+\frac{\alpha_{m}}{\tau}\right)\left\|J_{\alpha_{n}}^{M} x-x\right\| \\
= & \kappa_{1}(m)\left\|J_{\alpha_{n}}^{M} x-x\right\|, \\
& \forall n \geq m, \forall x \in \mathscr{H} .
\end{aligned}
$$

The same argument shows for all $m \in \mathbb{N}$ that

$$
\begin{array}{r}
\left\|J_{\beta_{m}}^{N} x-x\right\| \leq \kappa_{2}(m)\left\|J_{\beta_{n}}^{N} x-x\right\|, \\
\forall n \geq m, \forall x \in \mathscr{H} .
\end{array}
$$

Therefore, condition (iii) of Theorem 15 is true for $\left\{J_{\alpha_{n}}^{M}\right\}$ and $\left\{J_{\beta_{n}}^{N}\right\}$, and then the desired conclusion follows from Theorem 15.

Replacing $S$ and $T$ with $J_{\alpha}^{M}$ and $J_{\beta}^{N}$, respectively, in Theorem 19, we obtain the following result.

Theorem 21. Suppose that $M$ and $N$ are two maximal monotone operators on $\mathscr{H}_{1}$ and $\mathscr{H}_{2}$, respectively, and suppose that $A: \mathscr{H}_{1} \rightarrow \mathscr{H}_{2}$ is a bounded linear operator with adjoint $A^{*}$. Let $\left\{a_{n}\right\}$ be a sequence in $(0,1), \gamma \in\left(0,2 /\|A\|^{2}\right)$, and $\alpha, \beta \in$ $(0, \infty)$ and assume that the solution set $\Omega$ of problem (94) is nonempty. Start with any $x_{1} \in \mathscr{H}_{1}$ and define a sequence $\left\{x_{n}\right\}$ by

$$
x_{n+1}=J_{\alpha}^{M}\left[\left(1-a_{n}\right)\left(I-\gamma A^{*}\left(I-J_{\beta}^{N}\right) A\right)\right] x_{n} .
$$

Then, the sequence $\left\{x_{n}\right\}$ converges strongly to the minimum norm solution of problem (94) provided that the following conditions are satisfied: (i) $\lim _{n \rightarrow \infty} a_{n}=0$;

(ii) $\sum_{n=1}^{\infty} a_{n}=\infty$;

(iii) either $\sum_{n=1}^{\infty}\left|a_{n+1}-a_{n}\right|<\infty$ or $\lim _{n \rightarrow \infty}\left(\mid a_{n+1}-\right.$ $\left.a_{n} \mid / a_{n}\right)=0$.

Recall some facts in Section 1. For a nonempty closed convex subset $C$ of $\mathscr{H}$, let $f: C \times C \rightarrow \mathbb{R}$ be a function satisfying conditions (A1)-(A4), which are described in Section 1 . The solution set of the equilibrium problem

$$
\text { find } x^{*} \in C \quad \text { such that } f\left(x^{*}, y\right) \geq 0, \quad \forall y \in C
$$

is denoted by $\operatorname{EP}(f)$, which is equal to $\operatorname{Fix}\left(J_{\alpha}^{f}\right)$ for any $\alpha>0$, where $J_{\alpha}^{f}$ is a function on $\mathscr{H}$ into $C$ defined by

$$
\begin{gathered}
J_{\alpha}^{f} x=\left\{z \in C: f(z, y)+\frac{1}{\alpha}\langle y-z, z-x\rangle\right. \\
\geq 0, \forall y \in C\}
\end{gathered}
$$

for all $x \in \mathscr{H} . J_{\alpha}^{f}$ is a single-valued firmly nonexpansive mapping.

Theorem 22. Suppose that $C$ and $\mathrm{Q}$ are two nonempty closed convex subsets of $\mathscr{H}_{1}$ and $\mathscr{H}_{2}$, respectively, and suppose that A : $\mathscr{H}_{1} \rightarrow \mathscr{H}_{2}$ is a bounded linear operator with adjoint $A^{*}$. Let $f: C \times C \rightarrow \mathbb{R}$ and $g: Q \times Q \rightarrow \mathbb{R}$ be functions satisfying conditions (A1)-(A4). Suppose further that $\left\{a_{n}\right\},\left\{b_{n}\right\}$, $\left\{c_{n}\right\}$, and $\left\{d_{n}\right\}$ are sequences in $[0,1]$ with $a_{n}+b_{n}+c_{n}+d_{n}=1$ and $a_{n} \in(0,1)$ for all $n \in \mathbb{N}$. Let $\left\{\alpha_{n}\right\}$ and $\left\{\beta_{n}\right\}$ be sequences in $(0, \infty),\left\{\gamma_{n}\right\}$ a sequence in $\left(0,2 /\|A\|^{2}\right)$, and $\left\{e_{n}\right\}$ a bounded sequence in $\mathscr{H}_{1}$. Assume that the solution set $\Omega$ of the problem

$$
\begin{gathered}
\text { find } x^{*} \in \mathscr{H}_{1} \\
\text { so that } x^{*} \in E P(f), \quad A x^{*} \in E P(g)
\end{gathered}
$$

is nonempty. For any $u \in \mathscr{H}_{1}$, start with an arbitrary $x_{1} \in \mathscr{H}$ and define a sequence $\left\{x_{n}\right\}$ by

$$
x_{n+1}=a_{n} u+b_{n} x_{n}+c_{n} J_{\alpha_{n}}^{f}\left(I-\gamma_{n} A^{*}\left(I-J_{\beta_{n}}^{g}\right) A\right) x_{n}+d_{n} e_{n} .
$$

Then, the sequence $\left\{x_{n}\right\}$ converges strongly to $P_{\Omega} u$ provided that the following conditions are satisfied:

(i) $\lim _{n \rightarrow \infty} a_{n}=\lim _{n \rightarrow \infty}\left(d_{n} / a_{n}\right)=0, \sum_{n=1}^{\infty} a_{n}=\infty$, $\sum_{n=1}^{\infty} d_{n}<\infty$;

(ii) $\lim _{n \rightarrow \infty} \inf c_{n}\left(2 \gamma_{n}-\gamma_{n}^{2}\|A\|^{2}\right)>0, \lim _{n \rightarrow \infty} \inf b_{n} c_{n}>$ 0 ;

(iii) $\lim _{n \rightarrow \infty}$ inf $\alpha_{n}>0, \lim _{n \rightarrow \infty} \inf \beta_{n}>0$. 
Proof. Define two set-valued mappings $M_{f}$ and $N_{g}$ on $\mathscr{H}_{1}$ and $\mathscr{H}_{2}$, respectively, by

$$
\begin{aligned}
& M_{f}(x)= \begin{cases}\left\{z \in \mathscr{H}_{1}: f(x, y)\right. & \\
\geq\langle y-x, z\rangle, \forall y \in C\}, & \forall x \in C, \\
\emptyset, & \forall x \notin C ;\end{cases} \\
& N_{g}(u)=\left\{\begin{array}{cc}
\left\{w \in \mathscr{H}_{2}: g(u, v)\right. & \\
\geq\langle v-u, w\rangle, \forall v \in Q\}, & \forall u \in Q, \\
\emptyset, & \forall u \notin Q .
\end{array}\right.
\end{aligned}
$$

As shown in Takahashi et al. [21], the set-valued mapping $M_{f}$ (resp., $N_{g}$ ) is a maximal monotone operator with $\mathscr{D}\left(M_{f}\right) \subseteq C$ (resp., $\mathscr{D}\left(N_{g}\right) \subseteq Q$ ), and $J_{\alpha}^{M_{f}}=J_{\alpha}^{f}=\operatorname{EP}(f)$ for any $\alpha>0$ (resp., $J_{\beta}^{N_{g}}=J_{\beta}^{g}=\operatorname{EP}(g)$ for any $\beta>0$ ). With $M=M_{f}$ and $N=N_{g}$ in Theorem 20, the desired conclusion follows.

If $\mathscr{H}_{1}=\mathscr{H}_{2}=\mathscr{H}, C=Q, f=g$, and $A$ is the identity transformation on $\mathscr{H}$, then (102) is reduced to the usual equilibrium problem, and we have the following corollary.

Corollary 23. Suppose that $C$ is a nonempty closed convex subsets of $\mathscr{H}$ and $f: C \times C \rightarrow \mathbb{R}$ is a function satisfying conditions (A1)-(A4). Let $\left\{a_{n}\right\},\left\{b_{n}\right\},\left\{c_{n}\right\}$, and $\left\{d_{n}\right\}$ be sequences in $[0,1]$ with $a_{n}+b_{n}+c_{n}+d_{n}=1$ and $a_{n} \in(0,1)$ for all $n \in \mathbb{N}$. Let $\left\{\alpha_{n}\right\}$ and $\left\{\beta_{n}\right\}$ be sequences in $(0, \infty)$, and let $\left\{\gamma_{n}\right\}$ be a sequence in $\left(0,2 /\|A\|^{2}\right)$ and suppose that $\left\{e_{n}\right\}$ is a bounded sequence in $\mathscr{H}_{1}$. Assume that the solution set $\Omega$ of the problem

$$
\text { find } x^{*} \in \mathscr{H} \quad \text { so that } x^{*} \in E P(f)
$$

is nonempty. For any $u \in \mathscr{H}_{1}$, start with an arbitrary $x_{1} \in \mathscr{H}$ and define a sequence $\left\{x_{n}\right\}$ by

$$
x_{n+1}=a_{n} u+b_{n} x_{n}+c_{n} J_{\alpha_{n}}^{f}\left[I-\gamma_{n}\left(I-J_{\beta_{n}}^{f}\right)\right] x_{n}+d_{n} e_{n} .
$$

Then, the sequence $\left\{x_{n}\right\}$ converges strongly to $P_{\Omega} u$ provided that the following conditions are satisfied:

(i) $\lim _{n \rightarrow \infty} a_{n}=\lim _{n \rightarrow \infty}\left(d_{n} / a_{n}\right)=0, \sum_{n=1}^{\infty} a_{n}=\infty$,
$\sum_{n=1}^{\infty} d_{n}<\infty ;$

(ii) $\lim _{n \rightarrow \infty} \inf c_{n}\left(2 \gamma_{n}-\gamma_{n}^{2}\|A\|^{2}\right)>0, \lim _{n \rightarrow \infty} \inf b_{n} c_{n}>$ 0 ;

(iii) $\lim _{n \rightarrow \infty} \inf \alpha_{n}>0, \lim _{n \rightarrow \infty} \inf \beta_{n}>0$.

As shown in Blum and Oettli [7] that the variational inequalities, convex differentiable optimization, Nash equilibria in noncooperative games and so on can be formulated as equilibrium problems, we see that the pervious corollary may be applied to approximate solutions of all aforementioned problems. The readers may readily write down the details.

Just as Theorem 21 to Theorem 20, there are similar results corresponding to Theorem 22 and Corollary 23. We leave the work to readers.

\section{References}

[1] Y. Censor and T. Elfving, "A multiprojection algorithm using Bregman projections in a product space," Numerical Algorithms, vol. 8, no. 2-4, pp. 221-239, 1994.

[2] H.-K. Xu, "Iterative methods for the split feasibility problem in infinite-dimensional Hilbert spaces," Inverse Problems, vol. 26, no. 10, Article ID 105018, 2010.

[3] C. Byrne, "Iterative oblique projection onto convex sets and the split feasibility problem," Inverse Problems, vol. 18, no. 2, pp. 441453, 2002.

[4] C. Byrne, "A unified treatment of some iterative algorithms in signal processing and image reconstruction," Inverse Problems, vol. 20, no. 1, pp. 103-120, 2004.

[5] Y. Yao, W. Jigang, and Y.-C. Liou, "Regularized methods for the split feasibility problem," Abstract and Applied Analysis, vol. 2012, Article ID 140679, 13 pages, 2012.

[6] Y. Yao, Y.-C. Liou, and N. Shahzad, "A strongly convergent method for the split feasibility problem," Abstract and Applied Analysis, vol. 2012, Article ID 125046, 15 pages, 2012.

[7] E. Blum and W. Oettli, "From optimization and variational inequalities to equilibrium problems," The Mathematics Student, vol. 63, no. 1-4, pp. 123-145, 1994.

[8] K. Aoyama, Y. Kimura, and W. Takahashi, "Maximal monotone operators and maximal monotone functions for equilibrium problems," Journal of Convex Analysis, vol. 15, no. 2, pp. 395409, 2008.

[9] P. L. Combettes and S. A. Hirstoaga, "Equilibrium programming in Hilbert spaces," Journal of Nonlinear and Convex Analysis, vol. 6, no. 1, pp. 117-136, 2005.

[10] E. Masad and S. Reich, "A note on the multiple-set split convex feasibility problem in Hilbert space," Journal of Nonlinear and Convex Analysis, vol. 8, no. 3, pp. 367-371, 2007.

[11] K. Goebel and W. A. Kirk, Topics in Metric Fixed Point Theory, vol. 28 of Cambridge Studies in Advanced Mathematics, Cambridge University Press, Cambridge, UK, 1990.

[12] J. B. Baillon, R. E. Bruck, and S. Reich, "On the asymptotic behavior of nonexpansive mappings and semigroups in Banach spaces," Houston Journal of Mathematics, vol. 4, no. 1, pp. 1-9, 1978.

[13] R. E. Bruck and S. Reich, "Nonexpansive projections and resolvents of accretive operators in Banach spaces," Houston Journal of Mathematics, vol. 3, no. 4, pp. 459-470, 1977.

[14] O. A. Boikanyo and G. Moroşanu, "Inexact Halpern-type proximal point algorithm," Journal of Global Optimization, vol. 51, no. 1, pp. 11-26, 2011.

[15] O. A. Boikanyo and G. Moroşanu, "Four parameter proximal point algorithms," Nonlinear Analysis: Theory, Methods \& Applications, vol. 74, no. 2, pp. 544-555, 2011.

[16] O. A. Boikanyo and G. Moroşanu, "A proximal point algorithm converging strongly for general errors," Optimization Letters, vol. 4, no. 4, pp. 635-641, 2010.

[17] S. Kamimura and W. Takahashi, "Approximating solutions of maximal monotone operators in Hilbert spaces," Journal of Approximation Theory, vol. 106, no. 2, pp. 226-240, 2000.

[18] G. Marino and H.-K. Xu, "Convergence of generalized proximal point algorithms," Communications on Pure and Applied Analysis, vol. 3, no. 4, pp. 791-808, 2004.

[19] R. T. Rockafellar, "Monotone operators and the proximal point algorithm," SIAM Journal on Control and Optimization, vol. 14, no. 5, pp. 877-898, 1976. 
[20] M. V. Solodov and B. F. Svaiter, "Forcing strong convergence of proximal point iterations in a Hilbert space," Mathematical Programming, vol. 87, no. 1, pp. 189-202, 2000.

[21] S. Takahashi, W. Takahashi, and M. Toyoda, "Strong convergence theorems for maximal monotone operators with nonlinear mappings in Hilbert spaces," Journal of Optimization Theory and Applications, vol. 147, no. 1, pp. 27-41, 2010.

[22] F. Wang and H. Cui, "On the contraction-proximal point algorithms with multi-parameters," Journal of Global Optimization, vol. 54, no. 3, pp. 485-491, 2012.

[23] H.-K. Xu, "A regularization method for the proximal point algorithm," Journal of Global Optimization, vol. 36, no. 1, pp.115125, 2006.

[24] H.-K. Xu, "Iterative algorithms for nonlinear operators," Journal of the London Mathematical Society, vol. 66, no. 1, pp. 240-256, 2002.

[25] P.-E. Maingé, "Strong convergence of projected subgradient methods for nonsmooth and nonstrictly convex minimization," Set-Valued Analysis, vol. 16, no. 7-8, pp. 899-912, 2008.

[26] Y.-Y. Huang and C.-C. Hong, "Approximating common fixed points of averaged self-mappings with applications to the split feasibility problem and maximal monotone operators in Hilbert spaces," Fixed Point Theory and Applications, vol. 2013, article 190, 2013.

[27] F. Wang and H.-K. Xu, "Approximating curve and strong convergence of the CQ algorithm for the split feasibility problem," Journal of Inequalities and Applications, vol. 2010, Article ID 102085, 13 pages, 2010. 


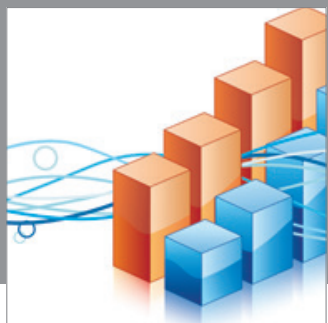

Advances in

Operations Research

mansans

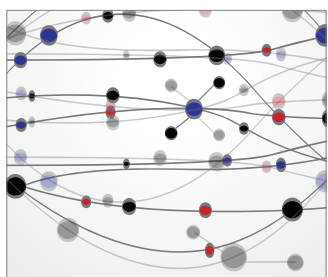

The Scientific World Journal
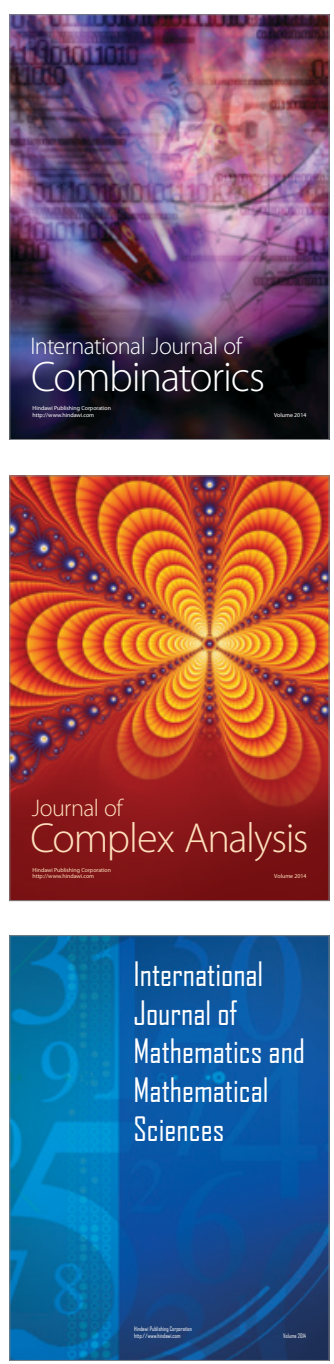
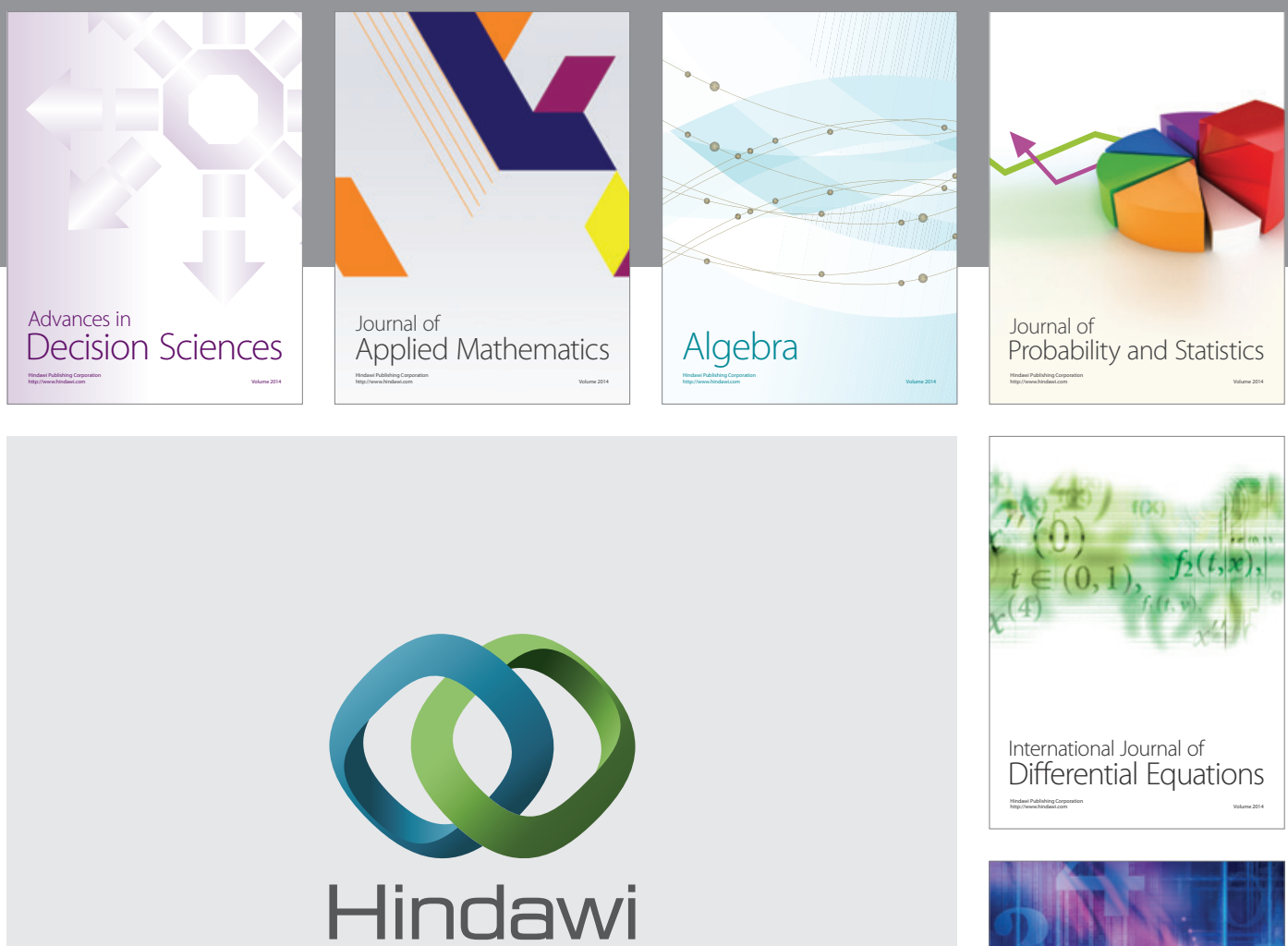

Submit your manuscripts at http://www.hindawi.com
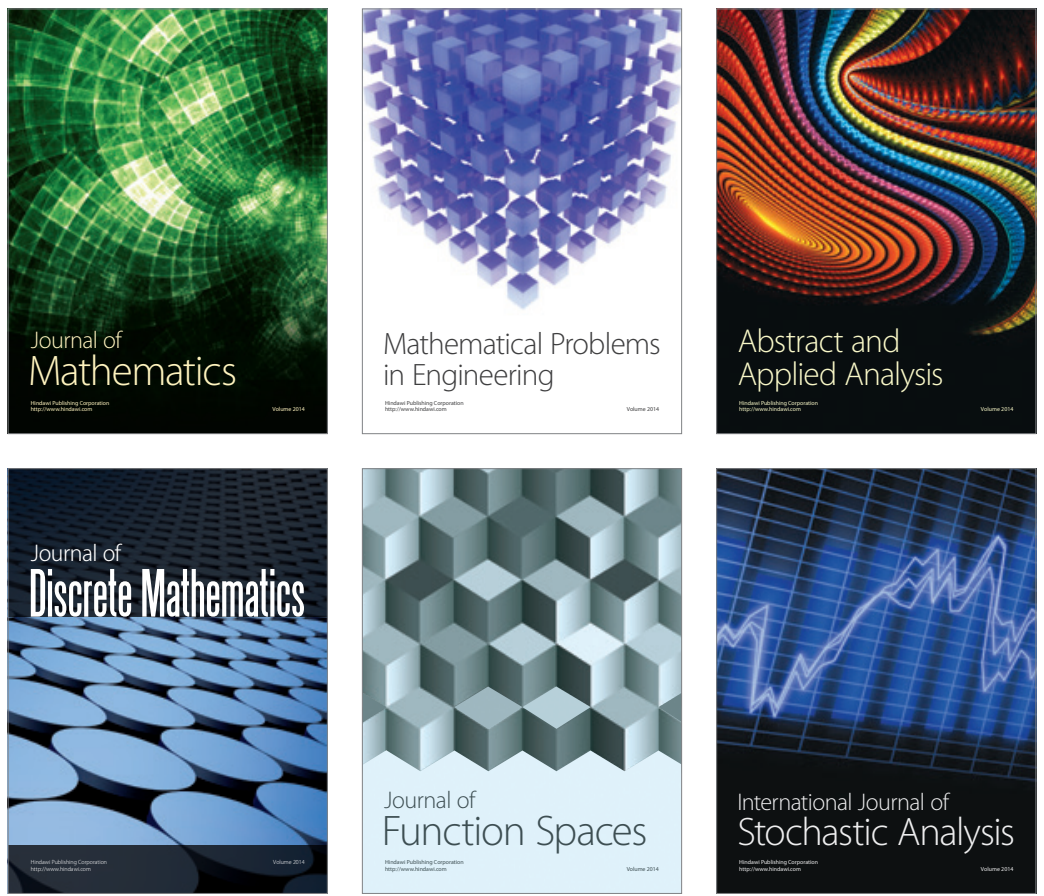

Journal of

Function Spaces

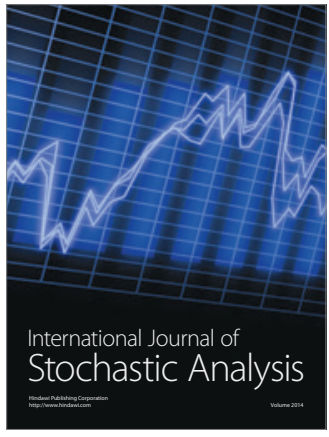

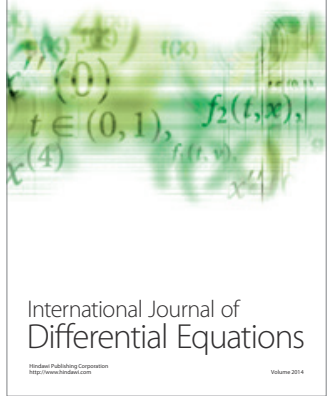
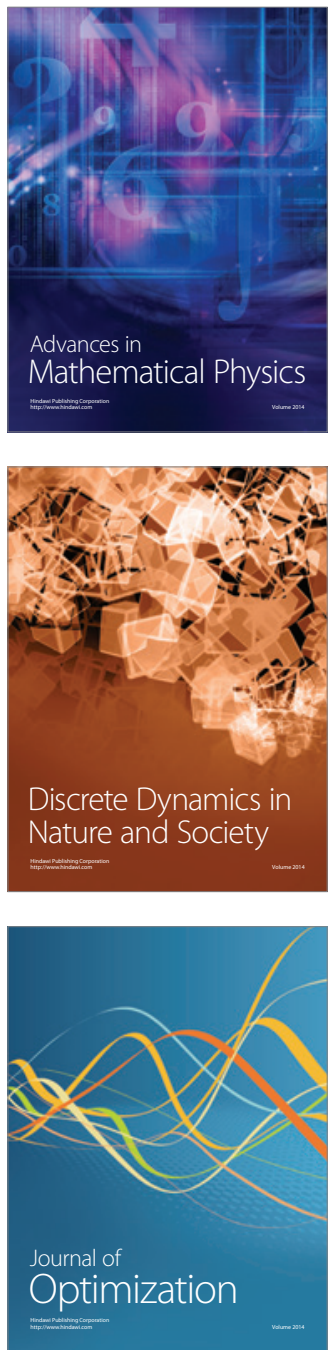